This item was submitted to Loughborough's Research Repository by the author.

Items in Figshare are protected by copyright, with all rights reserved, unless otherwise indicated.

\title{
Surface modification of an ambient UV-cured dielectric to realise electrically conducting traces
}

PLEASE CITE THE PUBLISHED VERSION

http://dx.doi.org/10.1016/j.surfcoat.2015.02.021

PUBLISHER

(C) Elsevier

VERSION

AM (Accepted Manuscript)

\section{PUBLISHER STATEMENT}

This work is made available according to the conditions of the Creative Commons Attribution-NonCommercialNoDerivatives 4.0 International (CC BY-NC-ND 4.0) licence. Full details of this licence are available at: https://creativecommons.org/licenses/by-nc-nd/4.0/

\section{LICENCE}

CC BY-NC-ND 4.0

\section{REPOSITORY RECORD}

Lim, Ying Ying, Yee M. Goh, Changqing Liu, and David A. Hutt. 2019. "Surface Modification of an Ambient Uvcured Dielectric to Realise Electrically Conducting Traces". figshare. https://hdl.handle.net/2134/17073. 


\section{Surface Modification of an Ambient UV-cured Dielectric to Realize Electrically Conducting Traces}

Ying Ying Lim, Yee Mey Goh, Changqing Liu, David Hutt

Wolfson School of Mechanical \& Manufacturing Engineering, Loughborough University, Epinal

Way, Loughborough, Leicestershire, LE11 3TU, United Kingdom

\section{Corresponding Author}

*E-mail: y.y.lim@lboro.ac.uk, Phone: +44 (0) 1509227684 


\begin{abstract}
There has been much interest in the printing of silver inks onto flexible substrates, for which intermediate dielectric layers are often required to achieve suitable wettability. This work seeks to realize continuous silver traces overprinted onto UV-curable dielectrics through surface modification techniques (thermal and UV-ozone post treatments), when the UV light source used for the curing is non-optimal. Two UV curable dielectric materials were deposited and the effects of curing time and curing atmosphere on the inkjet printability of a commercially available silver ink were investigated. Good wettability of the silver ink was obtained following ozone treatment of the dielectric layers, where the treatment required was found to be a function of the dielectric formulation and the curing atmosphere. Water droplet contact angle measurements were used to analyse the resulting changes in the surface conditions of the dielectric layers. The results provided an indication, but were not sufficient for predicting whether silver traces with measurable resistance could be subsequently obtained. Instead, measurable silver trace resistances were found to be influenced by the occurrence of cracks in the trace and possibly the degree of cross-linking present in the dielectric. Following these results, the authors demonstrate that electrically conductive traces can be achieved on ambient cured samples, which yields a more flexible solution compared to inert cured samples.
\end{abstract}

\title{
Keywords
}

De-wetting, UV-ozone treatment, Resistance, Inkjet printing, UV-curable dielectric, Contact angle 


\section{Introduction}

The merging of wireless technology with consumer electronics has made wearable electronics increasingly pervasive in everyday life, with applications spanning from the health and physiological monitoring of the wearer (e.g. patients, athletes) to military operations. Compared to traditional or mounted electronic devices, the key advantages include reduced weight, improved mobility and user comfort. From an electrical perspective, wearable electronics with low resistance interconnects are crucial for good performance [1], as this translates to low losses at higher frequencies, such as the millimetre-wave $(60-\mathrm{GHz})$ wireless body area network (WBAN).

From the literature, conductive traces have typically been realised on fabrics using either conductive threads [2, 3] or screen-printing [4, 5]. However, conductive threads are not suitable for high frequency applications because the plating thickness of conductive fabrics was found to be restricted to several hundred nanometers [2] in order to maintain textile properties. As such the implication of using conductive fabrics lies in the significant losses arising at higher frequencies due to the skin effect phenomenon. On the other hand, the main drawback of screen printing lies in the minimum dimension realisable. In contrast, inkjet printing, typically of a silver nanoparticle loaded ink, is an attractive alternative as it offers the viability of printing fine lines. In addition, it is possible to achieve thicker traces to alleviate the skin depth effect in high frequency applications by overprinting several layers of silver.

As fabrics are porous materials, a challenge exists in depositing silver nanoparticles to form conductive traces via inkjet printing. Typically an intermediate layer is required (i.e. surface modification of the fabric) to fill in the pores before the silver ink can be deposited to form conductive patterns [6,7]. However this introduces an added complexity in that the surface energies of the intermediate layer and silver ink have to match in order to prevent de-wetting from occurring[7, 8]. From the literature, others have accomplished this by customising either [9] or both [6] of the ink formulations of the intermediate layer and silver ink, such that electrically conductive traces can be formed. 
The present work focuses on obtaining measurable resistances for silver inks overprinted onto UV-curable dielectric layers, with the goal of printing onto fabrics. In this case, the focus is not on tuning the ink formulations or properties, but on understanding the processing parameters to eliminate de-wetting when the surface energies of the UV-curable dielectric and silver ink are not matched. One of the objectives of this paper is therefore to provide guidelines for realising electrically conducting traces on fabrics using commercial ink formulations, especially where the curing equipment available may be non-optimal. Consequently the authors then seek to eliminate de-wetting and achieve measurable resistance for silver traces overprinted onto the UV-curable dielectric layer. At this stage, optimization of the electrical resistivity of the printed traces has not been investigated, as literature abounds in this area [10, 11].

To simplify the study and analysis of the parameters affecting de-wetting, glass was used as the substrate in this work. Firstly as glass is non-porous, the influence of substrate porosity on the UV-curable dielectric layer can be ignored, particularly since the curing light source is nonoptimal. Another challenge in applying dielectric layers on textiles lie in the substrate surface roughness. Previous results from applying an insulator coat (SU-8) on a fabric yielded an uneven coating, where the parameters used for conventional silicon wafer processing were not found to suffice [7].

\section{Materials}

\subsection{Substrate}

The substrates used for coating with UV-curable inks were twin frosted glass slides of dimensions $76 \mathrm{~mm}$ x $26 \mathrm{~mm}$ with thicknesses in the range of 0.9-1.0 mm (Fisherbrand P/N 11562203, Fisher Scientific). The glass slides were cleaned with acetone and wiped using cleanroom wipes prior to usage.

\subsection{UV-Curable Dielectric Inks}

Two UV-Curable inks were selected for evaluation with the silver ink. EMD 6415 is a commercial product (SunTronic Solsys Jettable Insulator EMD 6415, Sun Chemical) which is formulated to yield a hard and non-porous surface after curing, such that it would be compatible 
with the overprinting of silver. The ink has a viscosity of $11-13 \mathrm{mPas}$ at $50{ }^{\circ} \mathrm{C}$ and a surface tension of $35-37 \mathrm{mN} \mathrm{m}^{-1}$ [12]. The specified cure dosage for EMD 6415 (un-doped mercury source) is from 100-300 mJ cm${ }^{-2}$. The second ink (SunTronic Solsys Jettable Insulator EMD 6200, Sun Chemical) is a research sample formulated for use with flexible substrates, with an ink viscosity of 7-9 mPas at $45^{\circ} \mathrm{C}$ and a surface tension of $23-27 \mathrm{mN} \mathrm{m}^{-1}$ [13]. At a temperature of $25^{\circ} \mathrm{C}$, the ink viscosity is $10-30 \mathrm{mPas}$ with a relative density of 1.02-1.1 [14]. The corresponding cure dosage required for EMD 6200 is $200-400 \mathrm{~mJ} \mathrm{~cm}^{-2}$. Both inks are formulated to react by radical polymerization and are colorless after coating.

\subsection{Silver Ink}

The ink used for the inkjet printing of metal traces is a composition of 20 wt \% silver (U8726/M20177, Sun Chemical), with a surface tension of $27-31 \mathrm{mN} \mathrm{m}^{-1}$. According to the datasheet, the ink contains no resin binders. The ink was selected based on its compatibility with the inkjet printer and EMD 6415. M20177 is formulated with a surfactant package to improve the spreading on the substrate surface. Nevertheless it is noted that M20177 has a similar surface tension to EMD 6200, which implies that the wettability of the silver ink onto EMD 6200 may not be as good compared to EMD 6415.

\section{Experimental Methods}

This section details the process of applying the UV-curable inks onto the glass slide substrates. It also describes the equipment and parameters used in the curing, surface modification and inkjet printing processes. Silver inks were printed onto two types of substrate configurations: plain glass slides and glass slides coated with UV-cured dielectric layers. The former were used to serve as reference samples to evaluate the printed traces on the latter.

\subsection{Ink Drawdown Process}

To coat glass slides with the UV-curable dielectric, a drawdown process was used. The drawdown process for coating the UV-curable dielectric onto the slides is shown in Figure 1. A glass slide was first placed on top of a metal plate and prevented from sliding by adhesive tape placed at one end. The UV-curable dielectric ink was then deposited onto the glass slide using a disposable pipette. Another glass slide was then used as an applicator to spread the ink across the 
glass substrate towards the tape, at an angle of $45^{\circ}$. Thicknesses of 20-30 $\mu$ m (EMD 6200) and $10 \mu \mathrm{m}$ (EMD 6415) were measured for the post-cured samples.

In this work, the samples prepared were compared to those supplied by the ink manufacturer (reference samples), which were drawn down using a K-bar to yield $24 \mu \mathrm{m}$ thickness. The reference samples were exposed using a H-bulb mercury lamp [15].

\subsection{UV Curing of the Dielectric Materials Under Inert and Ambient Environments}

The recommended equipment for curing the UV dielectrics is an undoped mercury (Hg) lamp $[12,13]$. In this work, the exposure unit used (Pluvex1410 UV Exposure Unit, Mega Electronics) [16] comprised of UVA bulbs operating in the range 315-400 nm with peak wavelength at 352 nm (Blacklight F15W/350 BL, Sylvania) [17]. The wavelength was noted to be within the recommended spectral distribution, although it does not cover the full spectrum from 200-600 $\mathrm{nm}[15]$.

The power intensity was measured with a UV light meter (UV-340A, Lutron Electronic Enterprise Co. Ltd) which measures the instantaneous power intensity values in the range of 290$390 \mathrm{~nm}$. Prior to measurements, the exposure unit was turned on for two rounds of 300 seconds, where 300 seconds is the recommended duration for obtaining constant exposure values [16]. Each round started 3-5 seconds after the last round. Following this, various exposure times ranging from 50-400 seconds were set, in steps of 50 seconds. Readings using the UV light meter were taken 4 times for each exposure time, to allow for the power intensity values to stabilise. The average power intensity value from the last reading (stabilised value) was then used to calculate the energy dosage. From the results obtained, the average energy dosage of the UV equipment was found to be $1.35 \pm 0.15 \mathrm{~mW} \mathrm{~cm}^{-2}$. This power intensity value is observed to be two orders of magnitude lower compared to a value of $150 \mathrm{~mW} \mathrm{~cm}{ }^{-2}$ used by the ink manufacturer [15], resulting in a prolonged exposure time.

During UV exposure in air, oxygen can diffuse into the ink and affect the cure reaction in a process known as oxygen inhibition [18, 19]. This phenomenon is exacerbated with extended exposure times and prevents a full cure of the dielectric layers (EMD 6200 and EMD 6415). In 
the absence of curing equipment with a light intensity strong enough to minimize oxygen inhibition, using an inert environment [20] during curing can help to alleviate oxygen inhibition. In this work the effect of curing the samples under different exposure atmospheres (inert versus ambient) was investigated. Specifically silver traces overprinted onto the different UV cured samples were compared in terms of their wettability, with the goal of obtaining electrically conductive traces.

For the inert curing, the glass slide samples were encapsulated in a polyethylene bag (100 mm x $140 \mathrm{~mm}$ ) filled with Argon gas. To minimize the oxygen present in the bag, argon gas was injected and expelled from the polyethylene bag three times before the final filling and sealing of the bag, Polyethylene was used in this work as it is largely transparent to UV light due to its simple chemical bonds [21]. To verify this, the power intensity values were measured again with the UV light meter inside a polyethylene bag. The measured values were observed to be comparable to those obtained without the polyethylene bag.

The UV dosages used for curing the dielectric samples ranged from $150-600 \mathrm{~mJ} \mathrm{~cm}^{-2}$, in intervals of $150 \mathrm{~mJ} \mathrm{~cm}{ }^{-2}$. The upper limit of $600 \mathrm{~mJ} \mathrm{~cm}^{-2}$ is in accordance with the recommendations of the ink manufacturer for good printability [22].

Another approach to alleviate the effects of oxygen inhibition is to use a secondary thermal cure, with the purpose of improving the cross-linking generated after the initial UV cure in an ambient atmosphere. From the literature [23, 24], authors have also used heat to promote thermal induced cross-linking of polymers. For instance Lee et al.[23] used microwave heating as an alternative to UV irradiation to generate thermally induced crosslinking in an acrylate. Samples which were subjected to a secondary thermal cure were placed in an oven for durations of 10 minutes at $150^{\circ} \mathrm{C}$. 


\subsection{UV-Ozone Treatment}

UV-ozone treatment ( $\left.\mathrm{UV} / \mathrm{O}_{3}\right)$ was used to modify the surface energy [25-28] of the dielectric layers after UV curing. Based on previous work [7], poor wettability was obtained for silver overprinted on the EMD 6200 dielectric layer. As such, the purpose of using UV-ozone treatment is to improve the wettability of the silver ink overprinted onto the dielectric layer. Much literature abounds in the use of UV-ozone treatment to obtain more hydrophilic surfaces [29-31], with the extent of hydrophilicity dependent on the UV-ozone exposure time [25-28].

The equipment used was a UV ozone photogenerator (PR-100 UV ozone photoreactor, UVP Inc.), which is a low pressure mercury source operating in the shortwave UV region. The output spectrum of the source displays two peaks in the UV-C band at $254 \mathrm{~nm}$ and $185 \mathrm{~nm}$ [32]. The UV power intensity is reported to be $15 \mathrm{~mW} \mathrm{~cm}^{-2}$ at a wavelength $254 \mathrm{~nm}$ and $1.5 \mathrm{~mW} \mathrm{~cm}^{-2}$ at $185 \mathrm{~nm}$ (at 1" distance from the source) [33]. To maximize the UV intensity reaching the samples, the samples were placed close to the UV source using a metal support such that the distance between the source and the samples was reduced to around $1 \mathrm{~cm}$.

The UV ozone exposure times were set from 20-80 seconds, as the system was not new and it was expected that the level of intensity would be lower. Assuming a $50 \%$ power rate, the equipment would yield maximum nominal exposures of $150 \mathrm{~mJ} \mathrm{~cm}^{-2}$ to $600 \mathrm{~mJ} \mathrm{~cm}^{-2}$ (at $254 \mathrm{~nm}$ ). Longer exposure times involving 3 minute intervals [25] were also considered in the study, in order to investigate a trend in the results obtained.

\subsection{Silver ink printing onto plain glass and UV-cured dielectric}

A commercial drop-on-demand mode inkjet printer (DMP 2831, Fujifilm Dimatix Inc.) was used for the silver ink deposition. The cartridge comprised of 16 nozzles capable of delivering $10 \mathrm{pl}$ drops per nozzle. In the printing of the silver ink onto the samples, a single jetting nozzle with a $5 \mathrm{kHz}$ waveform was used to print straight lines in the direction of travel of the platen. The inks were jetted out at temperatures of $28{ }^{\circ} \mathrm{C}$, with the dot spacing in the direction of travel maintained at $20 \mu \mathrm{m}$. $25 \mathrm{~mm}$ long traces with widths of $100 \mu \mathrm{m}, 500 \mu \mathrm{m}$ and $1 \mathrm{~mm}$ were deposited by making multiple passes of the single nozzle to print parallel lines with a centre to centre spacing of $20 \mu \mathrm{m}$. Prior to printing, these traces were created using a pattern definition 
program available in the inkjet printer software [34]. The samples were heated at $60{ }^{\circ} \mathrm{C}$ (platen temperature) during printing. Following that, the printed tracks were thermally sintered at $150{ }^{\circ} \mathrm{C}$ for 60 minutes.

Some samples were overprinted with two layers of silver ink, to ascertain the effect on the resistance values. The second silver layer was printed after a 15 minute interval following the printing of the first layer on the heated platen. After the second silver layer was printed, the samples were thermally sintered at $150{ }^{\circ} \mathrm{C}$ for 60 minutes.

\subsection{Sample Characterization}

A number of techniques were used to characterize the samples at different stages of the process in order to evaluate the surface properties and printability.

\subsubsection{Contact Angle Measurements}

In order to realise conductive traces, it is crucial that good wettability first be obtained for the silver ink deposited onto the UV-cured dielectric layer. To evaluate wettability, contact angle measurements were performed on the dielectric layer following which the respective surface energies were calculated. The contact angles were obtained for coated glass slides cured under different conditions, with/without UV-ozone treatment.

An assumption behind obtaining reliable contact angle values is that there exists minimal absorption of the liquid into the test surface [35]. In this work, the UV-cured polymers considered have varying degrees of cross-linking under inert and ambient environments. To minimize the interaction between the reference liquid and the UV-cured polymer, the choice of a suitable reference liquid becomes an important consideration in the contact angle measurements.

In addition to contact angle measurements, attempts were made to characterize the sample surfaces with the calculated surface energy values using the Owen-Wendt-Rabel-Kaelble method [36]. This method requires the contact angle measurements of the samples using two reference liquids, where triply distilled water and diiodomethane were used. In using diiodomethane for contact angle measurements, imprints and smudging were observed on the surfaces of EMD 6200 samples after wiping away the diiodomethane droplets, which suggested that the dielectric 
layer may have been partially dissolved by diiodomethane. Apart from the incompatibility of the liquid with the polymer, the solubility observed could also have been due to the incomplete curing of the UV ink when cured under an ambient environment, particularly since EMD 6200 is noted to have a reduced cross-linking formulation. As the accuracy of the contact angle measurements depend on the purity of the reference liquids, what was observed may indicate a degradation of the purity of diiodomethane, which could have affected the contact angle results.

To eliminate the uncertainty arising from the interaction of a solvent with the polymer, only one reference liquid, triply distilled high purity water (Chromasolv for HPLC, Sigma-Aldrich), which was not found to react with the polymer was used for the contact angle measurements. From the literature, the contact angles of water have been used to determine the wettability of polymers and corona treated surfaces [37].

The contact angle measurements of water were obtained using a Fibro DAT 1100 contact angle tester (Fibro System AB, Sweden), where a minimum of three static contact angle measurements were obtained for each surface modified substrate. The contact angle measurements (using the sessile drop method) were recorded for a period of 10s following the droplet deposition. The measured values were observed to approximate the contact angles after 1s droplet deposition. The droplet volumes used in the measurements were $2.0 \pm 0.5 \mu \mathrm{l}$. These values were repeated using the sessile drop method with a Dataphysics OCA20 system, where a variation of $\pm 4^{\circ}$ was observed compared to the values obtained with the Fibro DAT 1100.

\subsubsection{Focused Ion Beam- Scanning Electron Microscope (FIB-SEM)}

To study the thin film and bulk material regions of the samples, a dual beam (FIB-SEM) microscope system (Nova 600 Nanolab Dual Beam, FEI) was used to do in-situ cross-sectioning of the printed silver trace on the glass slide. This method is preferable to manual cross-sectioning as with that approach the cleaved edge may be non-uniform and small pieces of glass may be deposited across the silver traces, contaminating the sample. Prior to making the cross-sections, dummy layers of palladium $(\sim 1 \mu \mathrm{m})$ were deposited onto the trace surfaces to serve as protective layers. 


\subsubsection{Optical Microscope}

A high power optical microscope (SMZ1500, Nikon) was also used to image the printed traces on the samples. The images were captured using $\mathrm{x} 0.75$ to $\mathrm{x} 3$ objective lenses.

\section{Results and Discussion}

\subsection{Silver ink printing on glass and UV cured dielectric layers}

The spreading of the silver ink on different substrates was investigated and Figure 2 shows examples of traces obtained after sintering that display different degrees of wettability. Initially, traces were printed on plain glass (Figure 2(A)) and these displayed good wettability, without any de-wetting. For traces defined with $1 \mathrm{~mm}$ widths in the inkjet printer, dimensions of 1.7-1.9 mm were obtained for the printed traces on plain glass, indicating significant spreading.

Figure 2(B) shows the traces overprinted on the EMD 6415 UV cured dielectric layer (UV cured in air for 230 seconds, $300 \mathrm{~mJ} \mathrm{~cm}^{-2}$ ) and without any subsequent surface modifications. Beading of the silver ink is observed due to poor wettability. Some improvement in the wettability of the traces was obtained (Figure 2(C)) after the EMD 6415 sample was subjected to a secondary thermal cure $\left(10\right.$ minutes, $\left.150^{\circ} \mathrm{C}\right)$ after UV curing to increase the cross-linking in the UV dielectric layer. However, the insufficient wettability of the silver ink onto the dielectric layers necessitated the use of UV-ozone treatment, following which good wettability was obtained, as shown in Figure 2(D), where clear linear traces can be seen. It was found that for the UV curing conditions used here (ambient atmosphere) that a minimum ozone exposure time of 80 seconds was required for all the UV cure dosages in order to generate clear linear traces.

The dielectric layers which were UV-cured under an ambient atmosphere were noted to remain tacky after the curing process and indicated that oxygen inhibition of the curing process may have taken place. In contrast, the manufacturer's reference samples that were cured with a more intense UV source were found not to be tacky. To investigate the effect of curing atmosphere EMD 6415 samples were UV-cured in the range of 150-600 $\mathrm{mJ} \mathrm{cm}^{-2}$ under an inert atmosphere and overprinted with the silver ink. Partial wettability similar to the image in Figure 2(C) was observed. Under these conditions, the traces were not found to be tacky, but good printability was 
not obtained. However, in contrast to the air cured samples that required $80 \mathrm{~s}$ ozone exposure to achieve printability, good wettability of the silver ink on the inert atmosphere cured surfaces was observed after only 20 seconds of ozone treatment (Figure 2(E)). The difference is attributed to the variation in the degree of cross-linking obtained when UV curing the EMD 6415 samples under an ambient atmosphere. This was the case for all the UV cure dosages used, indicating that these are within the range for good printability. For EMD 6415 samples cured under both inert and ambient atmospheres, where silver ink traces were obtained, printed trace widths of 1.5-1.6 mm were observed for a designed trace width of $1 \mathrm{~mm}$. This again indicates spreading of the silver ink, similar to that observed with the plain glass substrate.

EMD 6200 samples were also prepared and tested for printability of the silver ink. Similar to the EMD 6415 material, it was found that samples cured in an ambient atmosphere were not wettable (Figure 2(F)). UV-ozone treatment was again used on these materials and the effect of curing in an inert atmosphere was also investigated. For samples cured under an inert environment, the UV-ozone treatment time required to obtain good wettability was 3 minutes. This was doubled to 6 minutes when curing the sample under an ambient atmosphere (Figure 2(G)). Smaller printed trace widths of $0.96-0.98 \mathrm{~mm}$ were obtained for a $1 \mathrm{~mm}$ width defined in the printer. The results indicate that ozone treatment is a key factor in eliminating de-wetting, with the required ozone treatment influenced by the degree of cross-linking present in the UV-curable dielectric layers. In turn the degree of cross-linking is influenced by factors such as the UV cure atmosphere (i.e. inert or ambient) as well as the ink formulations [38, 39].

\subsubsection{Cracking in silver traces on EMD 6200}

For the EMD 6200 samples cured in an inert atmosphere and subjected to ozone treatment, cracks could be observed for a single layer of silver ink overprinted and thermally sintered as shown in Figure 3(A). This phenomenon is exacerbated with two layers of silver overprint under the same UV exposure and ozone treatment conditions (Figure 3(B)), where pronounced hairline cracks were observed. In contrast, no cracks were observed for EMD 6415 samples which were exposed under an inert atmosphere and ozone treated. There were also no cracks observed for traces printed onto plain glass slides (Figure 2(A)), or for EMD 6200 samples cured under an ambient atmosphere. 
For the single layer of silver overprint, the cracks were observed to occur at the edges of the 500 $\mu \mathrm{m}$ and $1 \mathrm{~mm}$ trace. This is attributed to the coffee stain effect where there is an outward fluid flow to compensate for the evaporative effect of a pinned contact line. Consequently the thickness at the trace edge is higher than the trace centre. From the literature, crack formations have been reported to occur for thicker films [40] and films which are above a certain critical thickness [41, 42]. When the silver overprint was increased to 2 layers, a wider crack area was observed for the smaller traces $(100 \mu \mathrm{m}$ and $500 \mu \mathrm{m})$, while the cracks for the $1 \mathrm{~mm}$ trace remained at the edges (Figure 3(B)). Compared to Figure 3(A), the crack area is also more obvious visually. This is since an increased layer of overprint also increases the line thickness, which would exacerbate the non-uniform solvent evaporation and gradient of solvent concentration [10]. The crack morphology in Figures 3(A) and 3(B) obtained by varying the layers of silver overprint was also observed to be different. While the trace in Figure 3(A) comprised of curved cracks, Figure 3(B) shows a straight array of cracks for 2 layers of silver overprint. From the literature, films with increased thickness have been found to yield an increase in the orderliness of the crack patterns [43, 44]. The resulting crack morphology is mainly attributed to changes in the humidity and temperature distribution of the evaporating (solvent) system [45].

Contrary to the observations of Lee et al. of the absence of cracks for narrower lines (100 $\mu \mathrm{m}$ widths) [10], the cracks in this study were seen to occur for both narrow and wide traces on the EMD 6200 samples cured under an inert atmosphere. While Lee et al. reported cracks for silver printed directly onto polyimide (PI) and glass, the traces in this work were printed on an intermediate dielectric layer. As such, this suggests stresses arising from the dielectric layer and/or printed silver layer cause the occurrence of cracks. In this case the contact line of the silver trace is pinned to the dielectric layer underneath [46]. As such any non-uniform shrinkage arising from the dielectric layer (EMD 6200) expansion/contraction during and after sintering would likely initiate stress. As EMD 6200 is formulated for flexible substrates, the dimensional shift that occurs is also expected to be larger compared to EMD 6415, for which no cracks were observed for samples cured under an inert atmosphere. The stress initiated could have resulted in the cracks observed in the silver traces, where the traces are unable to shrink in-plane due to its adherence to the dielectric layer [46, 47]. 
In addition, the cracks could stem from residual thermal stresses arising from the coefficient of thermal expansion (CTE) mismatch between the silver ink and the underlying UV insulator during thermal sintering and upon cooling after sintering. The silver traces on the EMD 6200 would experience compressive residual thermal stresses due to the higher CTE of the insulator $\left(60-80 \mu \mathrm{m}^{\circ} \mathrm{C}^{-1}\right)$ [22] compared to the silver trace $\left(\alpha_{\mathrm{Ag}}=19.6 \mu \mathrm{m}^{\circ} \mathrm{C}^{-1}\right)$ [10, 40]. Furthermore an inhomogeneous stress distribution could have resulted during the solidification of the silver trace, where compression is generated in the bottom-most region (due to the CTE mismatch), while the top-most region could have remained in tension. Consequently the overall stress distribution of the trace-dielectric configuration would be more tensile.

Another factor contributing to the crack phenomenon could be due to the rate of solvent release if the remaining solvent present in the silver ink is released too quickly during sintering. Thus if the rate of evaporation is fast compared to the rate of transport of liquid to the surface [48], pressure and moisture gradients would arise, which results in non-homogeneous shrinkage [48]. This in turn generates tensile stresses, and cracks are initiated when the stresses exceed the tensile strength of the material [10].

For EMD 6200 samples which were exposed to prolonged UV-ozone treatments for 20 minutes or longer, cracks were still evident on the silver ink printed trace after thermal sintering (Figure 4). This phenomenon was observed for EMD 6200 samples exposed under inert and ambient atmospheres, but was significantly pronounced for those exposed under ambient atmospheres (Figure 4(A)). This could be attributed to a modification of the sample surface roughness due to the prolonged UV-ozone treatment time [31]. Jofre-Reche et al. reported changes to the surface topography of a polymer material with an increase in the UV ozone treatment time. These changes were attributed to the ozone and atomic oxygen ablation and etching of the material surface [31]. The EMD 6200 samples exposed under ambient atmosphere are expected to yield reduced cross-linking due to oxygen inhibition [38]. Compared to samples exposed under an inert atmosphere, this would result in an increased degree of softening of the polymer. Consequently the more pronounced cracking observed for the ambient exposed sample could be attributed to an increased ozone and oxygen ablation of the material [31]. Due to the colourless 
coating of EMD 6200, it was not possible to observe optically the surface topography of these samples.

In other research, the crack phenomenon observed has been shown to be controlled through the use of thinner films [49] and by tuning the insulator formulation [48, 49], which is out of the scope of this paper. The occurrence of cracks was found to affect the measurable resistance of the printed silver traces [10], as discussed further in Section 4.3.

\subsection{Contact Angle and Printability}

Figure 5 shows the contact angles for water on the UV cured dielectric layers and also indicates if printability of the silver ink was good. The contact angle results suggest that the values required for good wettability vary with the material and curing condition. For samples cured under an inert atmosphere (with a low intensity power source) and subjected to UV ozone treatment, slightly lower values of $74^{\circ}$ (EMD 6415) were obtained that gave good silver ink wetting. Samples cured under an ambient atmosphere and subjected to UV ozone treatment yielded values $\leq 62^{\circ}$ (EMD 6415) and $\leq 60^{\circ}$ (EMD 6200) for good printability. In contrast, the highest contact angles of $77-83^{\circ}$ were obtained for samples exposed to a high intensity power source (manufacturer samples), which generated highly cross-linked polymer networks where no dewetting occurred during the overprinting of the silver ink.

It can be observed that samples subjected to UV-ozone treatment yielded lower contact angles compared to those without. For EMD 6415 samples, the contact angles following UV ozone treatment (S8 and S9) are not significantly lower (3-7 $)$ compared to those without treatment (S7) due to the short ozone treatment times (20-80 s). However, the decrease in contact angle is more significant with longer treatment times [31], as observed for EMD 6200 samples S5 $\left(10^{\circ}\right.$ reduction) and $\mathrm{S} 6$ ( $30^{\circ}$ reduction) compared to $\mathrm{S} 3$.

An interesting phenomenon is observed for the samples exposed in an ambient atmosphere followed by a secondary thermal cure for durations of 10-20 minutes (S4, S5). For the EMD 6415 samples, the contact angle decreased after 10 minutes of thermal cure (Figure 2(C)), yet increased with a prolonged duration of 20 minutes. The results suggest that a shorter period of 
thermal cure would aid in the polymer cross-linking and in lowering the surface energy of the polymer. However, curing periods beyond 10 minutes suggest a hydrophobic recovery of the water contact angles with further thermal stimulation [50]. In contrast, a secondary thermal cure does not appear to improve the wettability for EMD 6200 samples. From Figure 5, 10 minutes of thermal curing resulted in a higher contact angle (by 13²) instead, when comparing S4 with S3. As EMD 6200 is formulated for flexible substrates, the ink would yield reduced cross-linking after curing compared to EMD 6415 [22]. The results imply a possible lack of thermally crosslinkable polymers in the ink. However, the results also suggest the possibility of using a secondary thermal cure to adjust the hydrophobicity of the layers to control the printing of silver inks to achieve finer line widths.

Overall, the contact angle provides a useful indication of printability through the ozone treatment duration required. In terms of comparison with literature, little information is available for contact angles obtained on partially cured polymers. For contact angle measurements made on UV cured films [51, 52], no information was provided on the final cure stage of those films, following which the authors assume that they are fully cured.

\subsection{Printability and Measurable Resistance}

Following the UV-ozone treatment of the insulators, single layers of silver ink were overprinted across the samples to form 0.5 and $1 \mathrm{~mm}$ (designed) trace widths which were $25 \mathrm{~mm}$ long. Three sets of such traces were printed onto the samples. After thermal sintering at $200{ }^{\circ} \mathrm{C}$ for 2 hours the trace resistances were measured using a 2 point probe digital multi-meter. In this case the higher sintering temperature and time were used (compared to the printability trials) to improve the resistance values obtainable. The results are shown in Figure 6, where the average resistance value per unit length (i.e. normalized resistance) was plotted for 3 different samples. For each sample, the average resistance value was obtained from at least two measurements. Specifically these resistance values were divided by the corresponding trace length over which the resistance was measured (in $\mathrm{cm}$ ) to normalize them. The results are presented without correcting for the trace widths or thicknesses. This is since the deposited ink volume is assumed to be constant [53], which implies that the cross-sectional areas of the traces would be the same (i.e. not affected by the trace spread) in the extraction of the resistance values. 
From the measurement results, it was observed that only samples prepared on dielectric layers exposed under an inert atmosphere and subjected to UV-ozone treatment gave conductive silver traces and yielded measurable resistances. This was the case for both EMD 6200 and EMD 6415 samples. From Figure 6, the normalized resistance for traces printed on plain glass consistently yield smaller values with smaller variation compared to the other samples. For $1 \mathrm{~mm}$ wide traces, the traces printed on plain glass yield normalized resistance values of $1.7-2.3 \Omega-\mathrm{cm}^{-1}$. This is at least 8 times lower compared to traces printed on EMD 6415 and EMD 6200 samples. In contrast, EMD 6415 and EMD 6200 samples yield a wide variation for the normalized resistance values. A range of 13.5-28.6 $\Omega-\mathrm{cm}^{-1}$ was obtained for EMD 6415 samples. For EMD 6200 samples prepared under the same conditions, this variation is slightly higher at 19.0-61.4 $\Omega-\mathrm{cm}^{-1}$. Since the trace resistance is based on how good an electrical path is formed, the results could be possibly attributed to two factors. The first is the formation of cracks in the samples exposed in an inert atmosphere, which has been discussed in Section 4.1.1. Consequently a variation in the crack density in each trace would result in a variation of the measured resistances as the electrical contacts between nanoparticles are obstructed by the crack openings [10].

A second factor causing the variation of the resistance values could be the degree of cross-linking present in the dielectric layers, which results in an inconsistency of the silver nanoparticle aggregation and hence the electrical path formed. This was further investigated using FIB-SEM. Figure 7(A) shows a FIB cross-section taken through the sintered trace to a part of the glass substrate underneath. From Figure 7(A), the silver nanoparticles deposited on plain glass were observed to be densely agglomerated without any clear boundary between the particles. In comparison, the silver nanoparticles observed in Figure 7(B) which shows a section through the sintered trace and part of EMD 6200 are less densely aggregated and appear to be suspended. Furthermore, the silver layer appears to be thicker on the EMD 6200 compared to on glass, which could be partly attributed to the increased spreading observed on glass.

Further FIB-SEM cross-sections made for an EMD 6200 sample at the centre and edge of the silver trace indicate that the thickness is not uniform. Figure 8(A) shows the top view of the sintered trace while Figure 8(B) and Figure 8(C) show the cross-sections taken of the trace into the EMD 6200 dielectric underneath. These cross-sections were taken at different locations 
(centre and edge) of the same trace in Figure 8(A), and dummy layers of palladium were deposited prior to making the cross-sections in Figures 8(B) and 8(C). From Figure 8(B), the thickness of the trace is $0.9-1.6 \mu \mathrm{m}$. This thickness is reduced to $\leq 1 \mu \mathrm{m}$ near the trace edge region as shown in Figure 8(C). In particular the trace thickness in the middle of the cross-section (Figure 8(C)) appears to be significantly smaller compared to the trace edges. The thickness variation could be due to the cross-section being taken near the junction of two dots located at the edge of the trace (Figure 8(A)), since further observation of the trace in Figure 8(A) reveals a dot-like appearance.

The dot-like appearance observed comprised of the deposited ink droplets which have not merged together, with the phenomenon being more obvious at the trace edge in Figure 8(A), where isolated droplets are observed. These isolated droplets could have been suspended in the dielectric layer and thus prevented from agglomerating. As the polymer is not fully cross-linked, the lessened polymer cross-linkages in EMD 6200 could have enabled a diffusion of the silver nanoparticles through the dielectric layer as the solvents in the silver ink penetrate the film, thereby providing a pathway underneath the dielectric layer. This is consistent to the crosssection observed in Figure 7(B) of the sintered trace, where the silver nanoparticles appear to be suspended within the EMD 6200 dielectric layer.

Overall, the results imply that the degree of cross-linking present in the UV-cured dielectric could be another factor affecting measurable resistance, since a continuous path is required for current to flow. As such, while traces could be printed without de-wetting onto samples exposed under an ambient atmosphere with UV-ozone treatment, no resistance values were measurable for those samples. In particular, the larger $1 \mathrm{~mm}$ trace widths were observed to yield a change in the colour shade at the trace edges (Figure 9). Goehring et al.[54] reported on such a phenomenon in the drying of colloidal dispersions. In particular, they observed a series of fronts when a colloidal suspension dries directionally, with distinct regions separating the liquid dispersion and the solid film [54].

While exposing the jettable insulators (EMD 6415, EMD 6200) under an inert atmosphere would be a more ideal condition for maximizing the polymer cross-linkages [38], the thermal sintering 
of the silver traces resulted in the occurrence of cracks as discussed earlier in Section 4.1.1. A few approaches exist to alleviate the crack phenomenon observed. One possibility is to adopt a localised curing of the silver traces [55-57] such as laser sintering or the use of a xenon flash lamp. This has been adopted for the thermal sintering of silver traces on temperature sensitive substrates and is thus a possibility for fabric substrates. However it may also be possible to apply this technique for the overprinted silver traces without residual thermal stresses arising from the CTE mismatch of the silver ink and the insulator. Yet the adoption of such a technique would require a silver ink with properties suitable for use with laser sintering. In addition, the use of a suitable laser source along with the optimisation of the laser sintering parameters for the ink is of critical importance [58]. Otherwise a non-ideal scalloped trace profile may result [56].

Another approach to alleviate cracks in the silver traces after thermal sintering involves a two stage drying process. Specifically the sample would be heated at a lower temperature $\left(70{ }^{\circ} \mathrm{C}\right.$ to $85{ }^{\circ} \mathrm{C}$ ) to partially remove the solvents, following which it would be subjected to a higher temperature for a shorter time for the sintering of the nanoparticles. Nevertheless, if the temperature is too high or the thermal curing duration too long, cracks can still occur if the solvent present in the silver ink is released too quickly during sintering.

\subsection{Electrically Conductive Traces on Ambient-Cured Dielectric Layers}

In view of the drawbacks of the above approaches, the authors considered curing the samples in an ambient environment, but overprinting upon it with multiple layers of silver ink to achieve measurable resistances. This is since crack formation is not an issue when curing the insulator samples under an ambient atmosphere. Due to the variation of the cross-linkages present in the ambient cured samples, the overprinting of multiple silver layers would aid in enhancing the proportion of the nanoparticles contacting and agglomerating during thermal sintering. In addition, the ambient cured samples would be thermally sintered for extended periods of time. This is to aid in the agglomeration of the nanoparticles to form conductive paths for measurable resistances.

Table 1 shows the resistances of $1 \mathrm{~mm}$ traces prepared from 2 layers of silver ink overprinted on ambient cured EMD 6415 samples. The dielectric layers were UV exposed using a dosage of 600 
$\mathrm{mJ} \mathrm{cm}^{-2}$ and ozone treated for 80 seconds. After printing the silver ink, the samples were thermally sintered at $150{ }^{\circ} \mathrm{C}$ for an extended period of 4 hours, followed by $180{ }^{\circ} \mathrm{C}$ for 1 hour. The extended period of 4 hours followed by a second stage of sintering at $180{ }^{\circ} \mathrm{C}$ is adopted to aid in the agglomeration of nanoparticles as proposed in Section 4.3.

From the results in Table 1, resistance values were registered after 4 hours of thermal sintering at $150{ }^{\circ} \mathrm{C}$. However, $50 \%$ of the resistance values are in the range of $\mathrm{k} \Omega$ and $\mathrm{M} \Omega$. After an additional hour of thermal sintering at $180^{\circ} \mathrm{C}$, most of the resistance values fall into the range of $\Omega$, with the least resistance being $23.2 \Omega$. The same procedure was performed for ambient cured EMD 6200 samples where two samples were subjected to a higher temperature thermal sintering of $180{ }^{\circ} \mathrm{C}$, in steps of 2 hours. The results obtained are also shown in Figure 10. It can be observed that sintering the overprinted traces at a higher temperature aids significantly in the agglomeration of the nanoparticles. From the FIB-SEM cross-section in Figure 11, increased clusters of silver particle agglomeration could be observed. After 4 hours of thermal curing, the measured normalized resistance values were in the range of $\Omega \mathrm{cm}^{-1}$ (Figure 10). Following an additional 2 hours of thermal curing at $180{ }^{\circ} \mathrm{C}$, the reduction in the normalized resistance was around $12 \%$. This suggests that a thermal curing of the traces at 2 hours may suffice since the reduction in the normalized resistance values is not significant after 4 hours. However it was noted that the error bar plots yield larger variations in the normalized resistance values after 4 hours of thermal cure. This implies that the degree of aggregation of the silver nanoparticles varies from trace to trace (albeit with the same trace width), which could be attributed to varying degrees of cross-linking present in different regions of the ambient cured insulator.

While the normalized resistance range obtained has to be further optimized, the results obtained show that the proposed approach is feasible for obtaining electrically conductive traces on ambient cured insulators, where the cross-linking in the samples are affected by oxygen inhibition. Compared to curing the samples under an inert environment, this yields a more flexible solution towards obtaining electrically connected traces. Further work would also be needed to improve the repeatability of the printed trace resistances. One possibility would involve improving the thickness variation of the coated insulators, such that a more uniform curing and hence improved cross-linking can be obtained. Overall, Figure 12 shows a summary 
of the operating window for achieving printability and measurable resistance on the UV-curable dielectric layers, based on a UV power source intensity of $1.35 \mathrm{~mW} \mathrm{~cm}^{-2}$.

\section{Conclusion}

This paper has investigated the preparation of continuous silver ink traces with measurable resistances on UV cured dielectric layers (EMD 6415, EMD 6200) with surface modifications. In particular, the goal was to provide guidelines for achieving electrically conductive traces using commercial ink formulations and where the curing equipment may be non-optimal. The important results of this work are summarized as follows:

- $\quad$ Silver ink de-wetting was observed on a number of substrates, and the influence of thermal and UV-ozone post treatments as surface modification techniques to eliminate the silver de-wetting were investigated for dielectric layers cured under both inert and ambient atmospheres. Good wettability of the overprinted silver ink on the dielectric layers (EMD 6415, EMD 6200) was obtained with UV-ozone treatment, where the treatment time required was found to be a function of the ink formulation, and the curing atmosphere which is thought to affect the degree of cross-linking.

- Water droplet contact angle measurements provided an indication of changes in the surface condition of the dielectric layers, but were not sufficient for predicting whether measurable silver track resistances could be obtained. Instead measurable resistance was found to be influenced by the occurrence of cracks. The results obtained also imply that the degree of cross-linking present in the dielectric could be another factor influencing measurable resistance. In this case, contact angle measurements serve as a precursor, but are not able to predict the performance of the silver trace deposited onto the UV-curable polymers in the post thermal sintering stage.

- The authors demonstrate that measurable resistance can be achieved on samples cured under an ambient atmosphere, through the overprinting of multiple silver layers and curing for an extended period of time. Compared to curing the samples under an inert atmosphere, this yields a more flexible solution to obtain electrically conductive traces. 


\section{Acknowledgements}

The authors are indebted to Dr Steve Jones and Dr Neil Chilton for allowing them access to the inkjet printers at Printed Electronics Limited and offering their expertise in printed electronics. They would also like to thank Mr Mike Pickrell from Sun Chemical for his invaluable technical support rendered in the evaluation of EMD 6200, and Mr Sam Moncur for his helpful inputs. In addition, the authors are grateful to Dr Steve Edmondson from the Department of Materials, Loughborough University, for the helpful discussions and allowing the authors access to the ozone photo-generator equipment. Lastly, the authors would like to acknowledge the 7th European Community Framework Programme for financial support through a Marie Curie International Research Staff Exchange Scheme (IRSES) Project entitled “Micro-Multi-Material Manufacture to Enable Multifunctional Miniaturised Devices (M6)” (Grant No. PIRSES-GA2010-269113). 


\section{References}

[1] S. Chung, J. Lee, H. Song, S. Kim, J. Jeong, Y. Hong, Appl. Phys. Lett., 98 (2011) 3.

[2] I. Locher, M. Klemm, T. Kirstein, G. Troster, IEEE Trans. Adv. Packag., 29 (2006) 777-788.

[3] T. Maleszka, P. Kabacik, Proc. Eur. Wireless Tech. Conf., Paris, France, Sept 27-28, 2010, pp. 89-92.

[4] B. Karaguzel, C.R. Merritt, T. Kang, J.M. Wilson, H.T. Nagle, E. Grant, B. Pourdeyhimi, J. Text. Inst., (2009) 1-9.

[5] S. Merilampi, Ph.D. Thesis, Tampere University of Technology, June 2011.

[6] A. Denneulin, J. Bras, A. Blayo, C. Neuman, Appl. Surf. Sci., 257 (2011) 3645-3651.

[7] Y.Y. Lim, Y.M. Goh, C. Liu, Ind. Eng. Chem. Res., 52 (2013) 11564-11574.

[8] A. Yakoub, M. Saadaouia, R. Cauchois, J.M. Li, P. Benaben, Proc. MRS Fall Meet.,Boston, Massachusetts, Nov 28-Dec 2, 2011, pp. 20-25.

[9] Y. Li, R. Torah, S. Beeby, J. Tudor, Proc. Text. Inst. World Conf., Selangor, Malaysia, May 15-17, 2012.

[10] D.J. Lee, J.H. Oh, H.S. Bae, Mater. Lett., 64 (2010) 1069-1072.

[11] H.C. Jung, S.-H. Cho, J.W. Joung, Y.-S. Oh, J. Electron. Mater., 36 (2007) 1211-1218.

[12] Technical Information Leaflet - SunTronic Solsys EMD6415 UV Curing Jettable Insulator; Sun Chemical Corporation, 2011.

[13] Technical Information Leaflet - SunTronic Solsys Jettable Insulator EMD6200; Sun Chemical Corporation, 2011.

[14] Clear UV Dielectric Ink EMD 6200 Safety Data Sheet, Sun Chemical Corporation, 2012.

[15] F300S and F300SQ Microwave-Powered Electrodeless Lamps (300 watt/inch), https://www.fusionuv.com (accessed Aug 23,2013).

[16] Pressure Line UV Exposure Unit PLUVEX 1410, http://www.megauk.com/uv_exposure_units.php (accessed Sept 15, 2013).

[17] Sylvania, Blacklight (BL-350) Datasheet, http://www.havells-sylvania.com (accessed Sept 15, 2013).

[18] M.L. Pilkenton, J.Chartoff, R., J. Appl. Polym. Sci., 119 (2010) 2359-2370.

[19] C. Decker, Macromol. Rapid Commun., 23 (2002) 1067-1093. 
[20] D.G. Anderson, S. Levenberg, R. Langer, Nature Biotech., 22 (2004) 863-866.

[21] J. Swenson, V. Calder, UV Penetration and Plastic, [Online] 2004, http://www.newton.dep.anl.gov/askasci/eng99/eng99272.htm (accessed Sept 30, 2013).

[22] M. Pickrell, Sun Chemical Ltd, Bath, UK, Personal communication, 2013.

[23] S.H. Lee, L. W.G., B.G. Chung, J.H. Park, A. Khademhosseini, Macromol.Rapid Commun., 30 (2009) 1382-1386.

[24] Y. Lei, Q. Niu, H. Mi, Y. Wang, I. Nurulla, W. Shi, Dyes Pigm., 96 (2013) 138-147.

[25] K.Y. Shin, S.H. Lee, J.H. Oh, J. Micromech. Microeng., 21 (2011) 045012 (11 pp).

[26] S. Luo, C.P. Wong, IEEE Trans. Comp. and Packag. Tech., 24 (2001) 43-49.

[27] D.E. King, J. Vac. Sci. Technol. A, 13 (1995) 1247-1253.

[28] K. Ma, J. Rivera, G.J. Hirasaki, S.L. Biswal, J. Colloid Interface Sci., 363 (2011) 371-378.

[29] R.O.F. Verkuijlen, M.H.A. van Dongen, A.A.E. Stevens, J. van Geldrop, J.P.C. Bernards, Appl. Surf. Sci., 290 (2014) 381-387.

[30] A. Peyvandi, S. Ul Abideen, Y. Huang, I. Lee, P. Soroushian, J. Lu, Appl. Surf. Sci., 289 (2014) 586-591.

[31] J.A. Jofre-Reche, J.M. Martin-Martinez, Int. J. Adhes. Adhes., 43 (2013) 42-53.

[32] J.R. Vig, IEEE Trans. Parts, Hybrids, Packag., PHP-12 (1976) 365-370.

[33] PR-100 UV-Ozone Photoreactor Operating Instruction Manual, UVP Inc.,USA.

[34] Dimatix Materials Printer DMP-2800 Series User Manual, Fujifilm Dimatix Inc.,USA, Jan 2007.

[35] B. Duncan, R. Mera, D. Leatherdale, M. Taylor, R. Musgrove,Technical Report for National Physical Lab, Middlesex, UK, Mar 2005.

[36] D.K. Owens, R.C. Wendt, J. Appl. Polym. Sci., 13 (1969) 1741-1747.

[37] M. Blitshteyn, Proc. TAPPI Polym., Laminations Coat. Conf., Nashville, TN, Aug 28-Sept 1,1994, pp. 189-195.

[38] K. Taki, T. Nakamura, J. Cosmet., Dermatol. Sci. Appl., 1 (2011) 111-118.

[39] C.P. Vazquez, R. Tayouo, C. Joly-Duhamel, B. Boutevin, J. Polym. Sci., Part A: Polym. Chem., 48 (2012) 2123-2134. 
[40] J.R. Greer, R.A. Street, J. Appl. Phys., 101 (2007).

[41] R.C. Chiu, T.J. Garino, M.J. Cima, J. Am. Ceram. Soc., 76 (1993) 2257-2264.

[42] R.C. Chiu, M.J. Cima, J. Am. Ceram. Soc., 76 (1993) 2769-2777.

[43] Y. Chan, Y. Mi, Polym., 45 (2004) 3473-3480.

[44] A. Groisman, E. Kaplan, Europhys. Lett., 25 (1994) 415-420.

[45] E.A. Jagla, Phys. Rev. E, 65 (2002) 046147 (7 pp).

[46] R.D. Deegan, Bakajin, O., Dupont, T.F., Huber, G., Nagel, S.R., Witten, T.A., Nat., 389 (1997) 827-829.

[47] H. Lei, L.F. Francis, W.W. Gerberich, L.E. Scriven, AIChE J., 48 (2002) 437-451.

[48] E. Santanach Carreras, F. Chabert, D.E. Dunstan, G.V. Franks, J. Colloid Interface Sci., 313 (2007) 160-168.

[49] A.F. Routh, Rep. Prog. Phys., 76 (2013) 046603 (30 pp).

[50] K. Nakata, H. Kimura, M. Sakai, T. Ochiai, H. Sakai, T. Murakami, M. Abe, A. Fujishima, Appl. Mater. Interfaces, 2 (2010) 2485-2488.

[51] T. Gururaj, R. Subasri, K.R.C. Soma Raju, G. Padmanabham, Appl. Surf. Sci., 257 (2011) 4360-4364.

[52] C.-S. Liao, C.-F. Wang, H.-C. Lin, H.-Y. Chou, F.-C. Chang, J. Phys. Chem. C, 112 (2008) 16189-16191.

[53] P.J. Smith, D. Shin, N. Reis, J. Stringer, B. Derby, J. Mater. Sci., 41 (2006) 4153-4158.

[54] L. Goehring, W.J. Clegg, A.F. Routh, Langmuir, 26 (2010) 9269-9275.

[55] S.H. Ko, H. Pan, C.P. Grigoropoulos, C.K. Luscombe, J.M.J. Frechet, D. Poulikakos, Nanotechnol.,18 (2007) 345202 (8pp).

[56] H.-S. Kim, S.R. Dhage, D.-E. Shim, H.T. Hahn, Appl. Phys. A, 97 (2009) 791-798.

[57] D. Tobjork, H. Aarnio, P. Pulkkinen, R. Bollstrom, A. Maattanen, P. Ihalainen, T. Makela, J. Peltonen, M. Toivakka, H. Tenhu, R. Osterbacka,Thin Solid Films, 520 (2012) 29452955.

[58] P. Laakso, S. Ruotsalainen, E. Halonen, M. Mäntysalo, A. Kemppainen, Proc. Int. Conf. Appl. Lasers Electro-Opt.(ICALEO), Orlando, Florida, Nov 2-5, 2009, pp. 1360-1366. 


\section{TABLE CAPTION LIST}

Table 1: Measured resistance values of $1 \mathrm{~mm}$ silver traces (2 layers) overprinted onto ambient cured EMD 6415 samples. 
Table 1 Measured resistance values of $1 \mathrm{~mm}$ silver traces (2 layers) overprinted onto ambient cured EMD 6415 samples.

\begin{tabular}{ccc}
\hline Line No. & $\mathbf{1 5 0}{ }^{\circ} \mathbf{C}, \mathbf{4}$ hours & $\mathbf{1 8 0}{ }^{\circ} \mathbf{C}, \mathbf{1}$ hour \\
\hline L1 & $1.47 \mathrm{k} \Omega$ & $191.9 \Omega$ \\
L2 & $0.37 \mathrm{k} \Omega$ & $75.8 \Omega$ \\
L3 & $70.8 \Omega$ & $39.9 \Omega$ \\
L4 & $47.5 \Omega$ & $23.2 \Omega$ \\
L5 & $1.79 \mathrm{M} \Omega$ & $0.51 \mathrm{k} \Omega$ \\
L6 & $83.3 \Omega$ & $31.4 \Omega$ \\
L7 & $1.71 \mathrm{M} \Omega$ & $91.0 \Omega$ \\
\hline
\end{tabular}




\section{FIGURE CAPTION LIST}

Fig. 1: Diagram illustrating the draw down process for the deposition of the UV insulator onto glass slide samples.

Fig. 2: Optical microscope images of silver ink traces (single layer) after printing and sintering on different substrates: (A) Plain glass; (B) EMD 6415 sample cured under an ambient atmosphere $300 \mathrm{~mJ} / \mathrm{cm}^{2}$; (C) EMD 6415 sample cured under an ambient atmosphere (300 $\mathrm{mJ} / \mathrm{cm}^{2}$ ) with secondary thermal cure applied (10 min); (D) EMD 6415 sample cured under an ambient atmosphere $\left(300 \mathrm{~mJ} / \mathrm{cm}^{2}\right)$ with UV-ozone treatment (80 s); (E) EMD 6415 sample cured under an inert atmosphere $\left(300 \mathrm{~mJ} / \mathrm{cm}^{2}\right)$ followed by UV-ozone treatment (20 s); (F) EMD 6200 sample cured under an ambient atmosphere $600 \mathrm{~mJ} / \mathrm{cm}^{2}$; (G) EMD 6200 sample cured under an ambient atmosphere $\left(600 \mathrm{~mJ} / \mathrm{cm}^{2}\right)$ followed by UV-ozone treatment (6 min).

Fig. 3: EMD 6200 samples exposed under: (A) Inert atmosphere followed by UV-ozone treatment (3 min) with one silver layer overprinted; (B) Inert atmosphere followed by UV-ozone treatment (3 min) with two silver layers overprinted.

Fig. 4: Silver ink traces on EMD 6200 samples cured under: (A) Ambient atmosphere, followed by UV-ozone treatment (30 min); (B) Inert atmosphere followed by UV-ozone treatment (30 $\min )$.

Fig. 5: Measured contact angles of water on dielectric layers prepared under different conditions. The notation “Good” refers to good silver ink printability where clear linear traces were obtained.

Fig. 6: Comparison of normalized resistance values for $1 \mathrm{~mm}$ wide (design width) silver traces printed on plain glass, EMD 6415 and EMD 6200 dielectric layers. The EMD 6415 and EMD 6200 samples were cured in an inert atmosphere with UV-ozone post treatments of 20 s and 2 min respectively. The errors bars in the figure represent the maximum and minimum values. 
Fig.7: FIB cross-section of sintered trace on: (A) plain glass; (B) EMD 6200 sample which was cured in an inert atmosphere and subjected to UV-ozone treatment for $2 \mathrm{~min}$.

Fig. 8: Silver ink printed on EMD 6200 which was cured in an inert atmosphere and subjected to UV-ozone treatment for 2 mins: (A) Top view of sintered trace; (B) Cross-section taken in the trace centre region; (C) Cross-section taken near the trace edge.

Fig. 9: Silver traces overprinted onto ambient cured dielectric samples: (A) EMD 6415 sample exposed under an ambient atmosphere and followed with UV-ozone treatment (80 s); (B) EMD 6200 sample exposed under an ambient atmosphere and followed with UV-ozone treatment (6 $\min )$.

Fig. 10: Variation of the normalized resistance values for $1 \mathrm{~mm}$ wide (design width) silver traces sintered for different periods of time at $180^{\circ} \mathrm{C}$. The results are for two layers of silver overprinted on ambient cured EMD 6200 samples.

Fig. 11: FIB cross-section showing clusters of agglomerated silver nanoparticles observed for two layers of silver overprinted on an ambient cured EMD 6200 sample.

Fig. 12: Summary of the operating window for achieving printability and measurable resistance on UV-curable dielectric layers (UV cure dosages of $150-600 \mathrm{~mJ} / \mathrm{cm}^{2}$ ), with respect to the UVozone treatment time. 


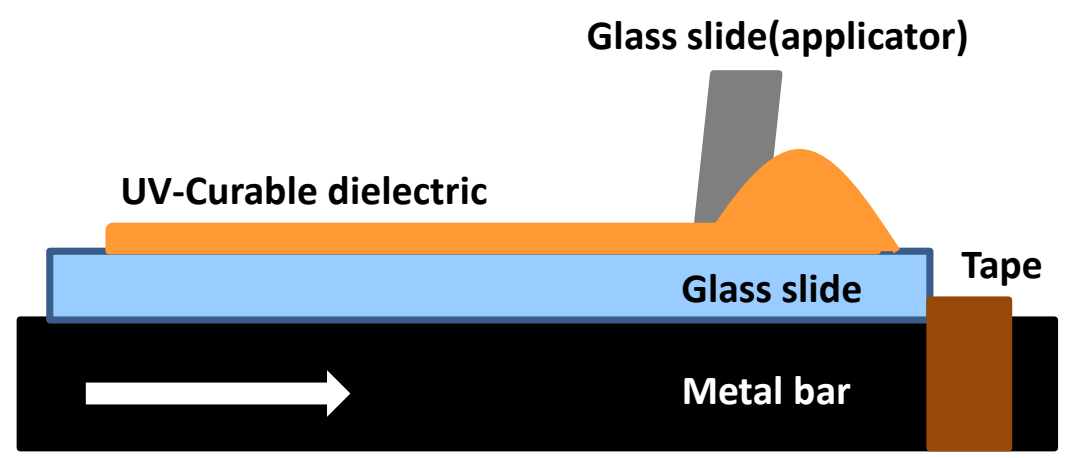

Fig. 1 Diagram illustrating the draw down process for the deposition of the UV insulator onto glass slide samples. 

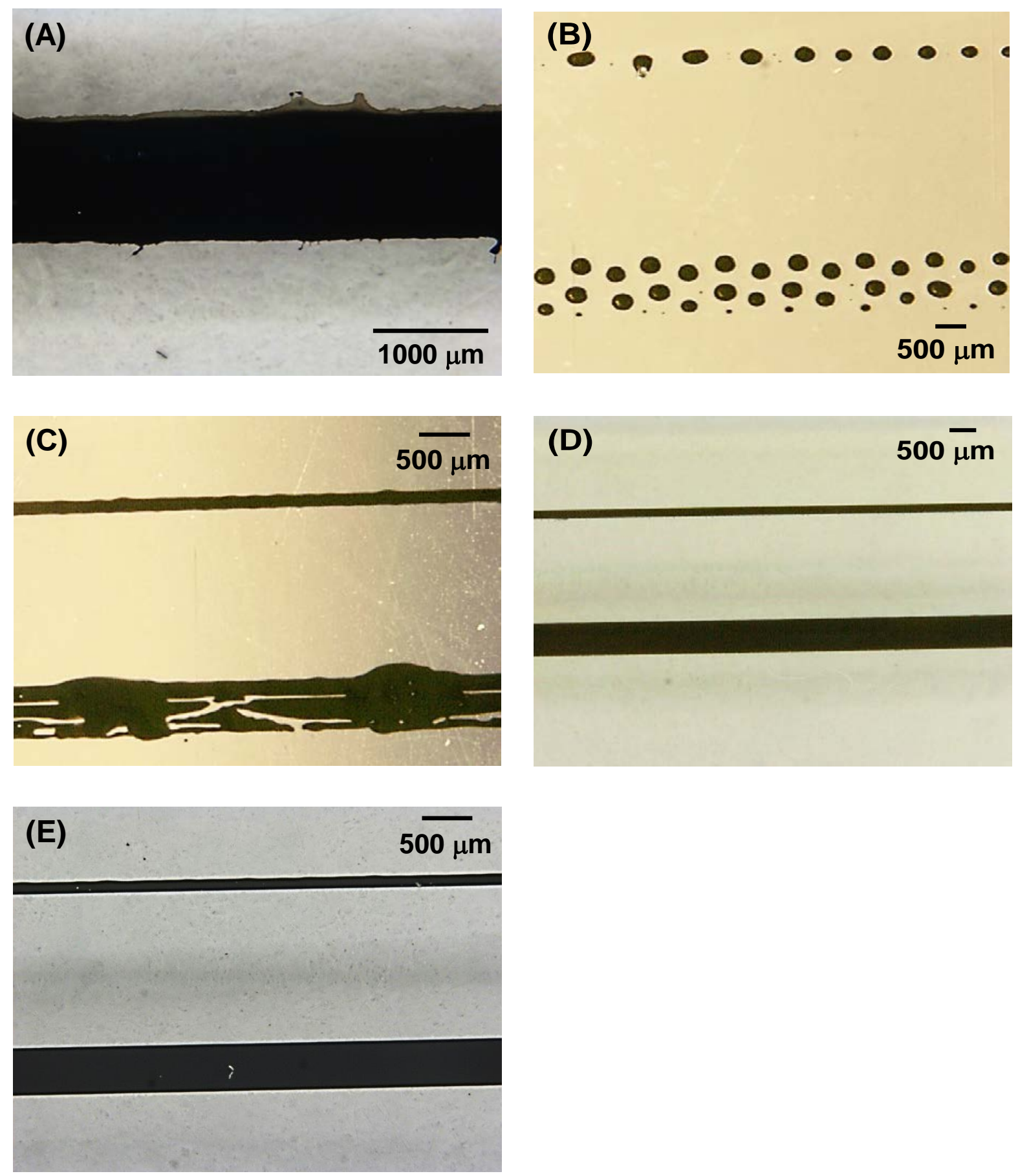

Fig. 2 Optical microscope images of silver ink traces (single layer) after printing and sintering on different substrates: (A) Plain glass; (B) EMD 6415 sample cured under an ambient atmosphere $300 \mathrm{~mJ} / \mathrm{cm}^{2}$; (C) EMD 6415 sample cured under an ambient atmosphere $\left(300 \mathrm{~mJ} / \mathrm{cm}^{2}\right)$ with 
secondary thermal cure applied (10 min); (D) EMD 6415 sample cured under an ambient atmosphere (300 mJ/ $\mathrm{cm}^{2}$ ) with UV-ozone treatment (80 s); (E) EMD 6415 sample cured under an inert atmosphere $\left(300 \mathrm{~mJ} / \mathrm{cm}^{2}\right)$ followed by UV-ozone treatment $(20 \mathrm{~s})$.
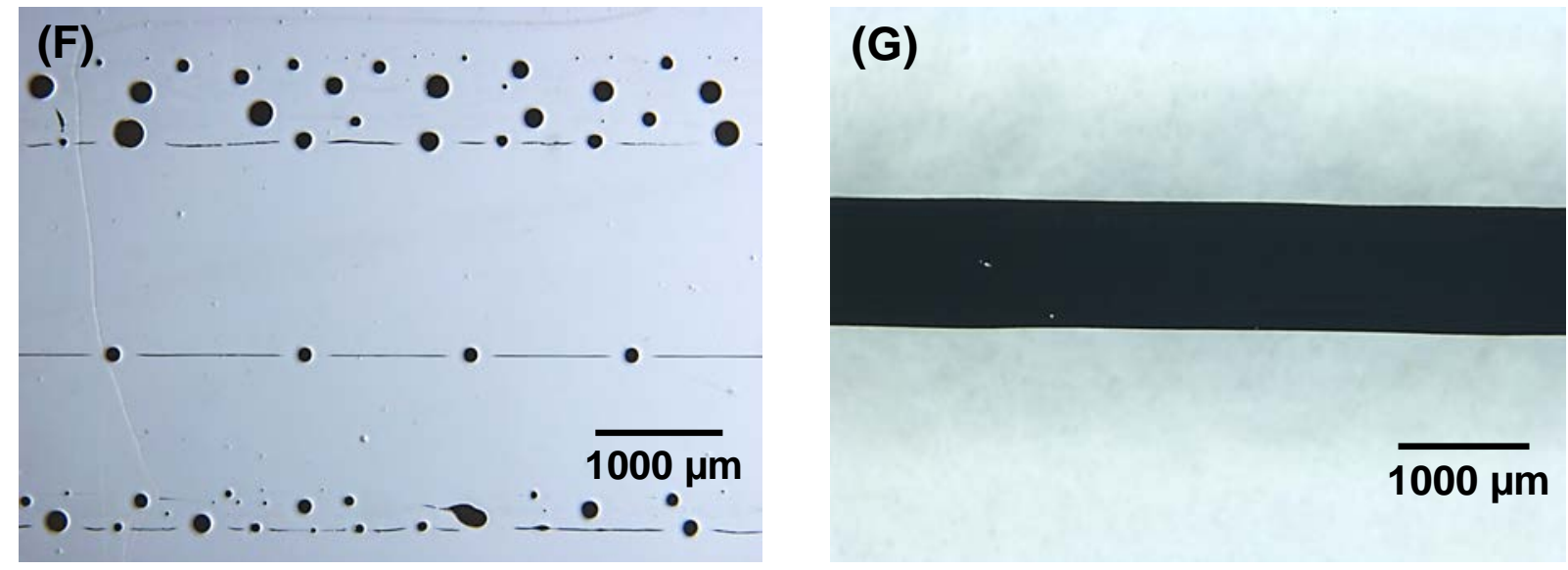

Fig. 2 (F) EMD 6200 sample cured under an ambient atmosphere $600 \mathrm{~mJ} / \mathrm{cm}^{2}$; (G) EMD 6200 sample cured under an ambient atmosphere $\left(600 \mathrm{~mJ} / \mathrm{cm}^{2}\right)$ followed by UV-ozone treatment (6 $\min )$. 


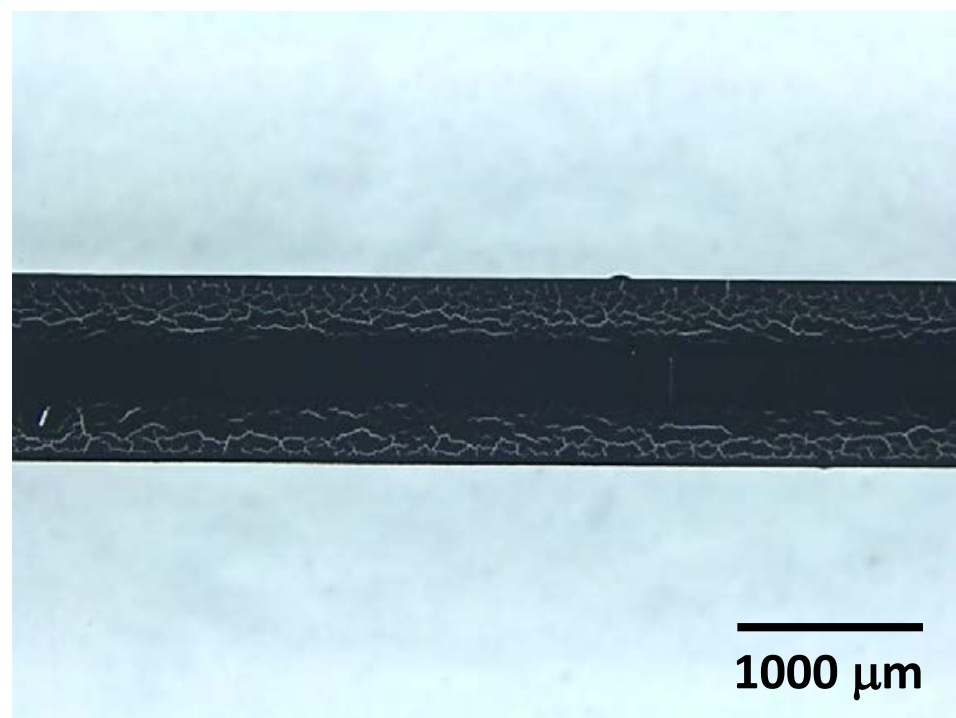

(A)

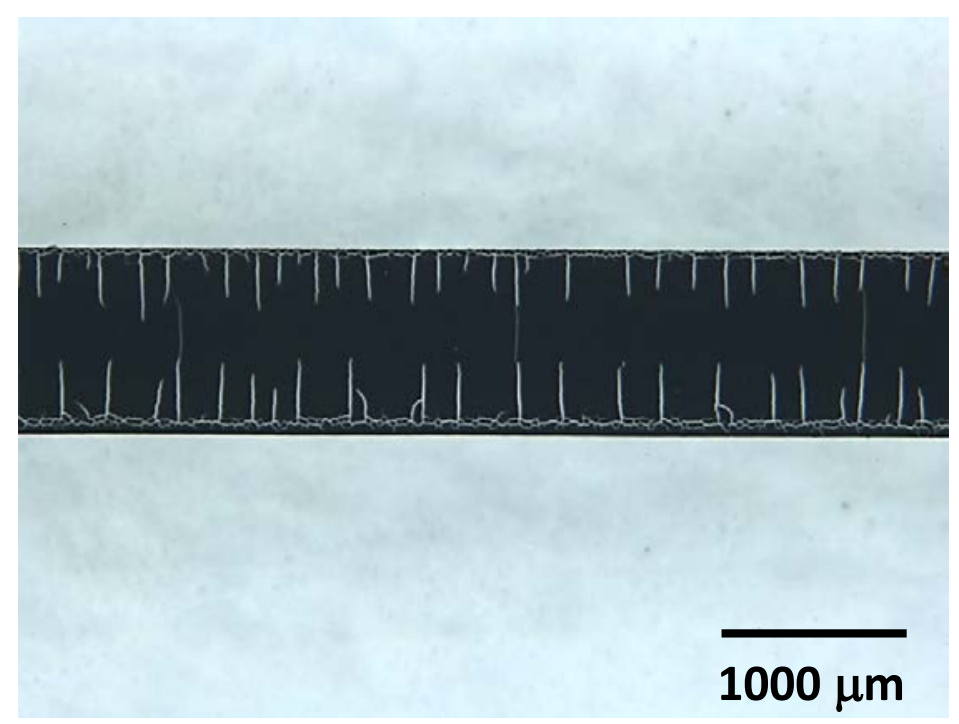

(B) 
Fig. 3 EMD 6200 samples exposed under: (A) Inert atmosphere followed by UV-ozone treatment (3 min) with one silver layer overprinted; (B) Inert atmosphere followed by UV-ozone treatment (3 min) with two silver layers overprinted.

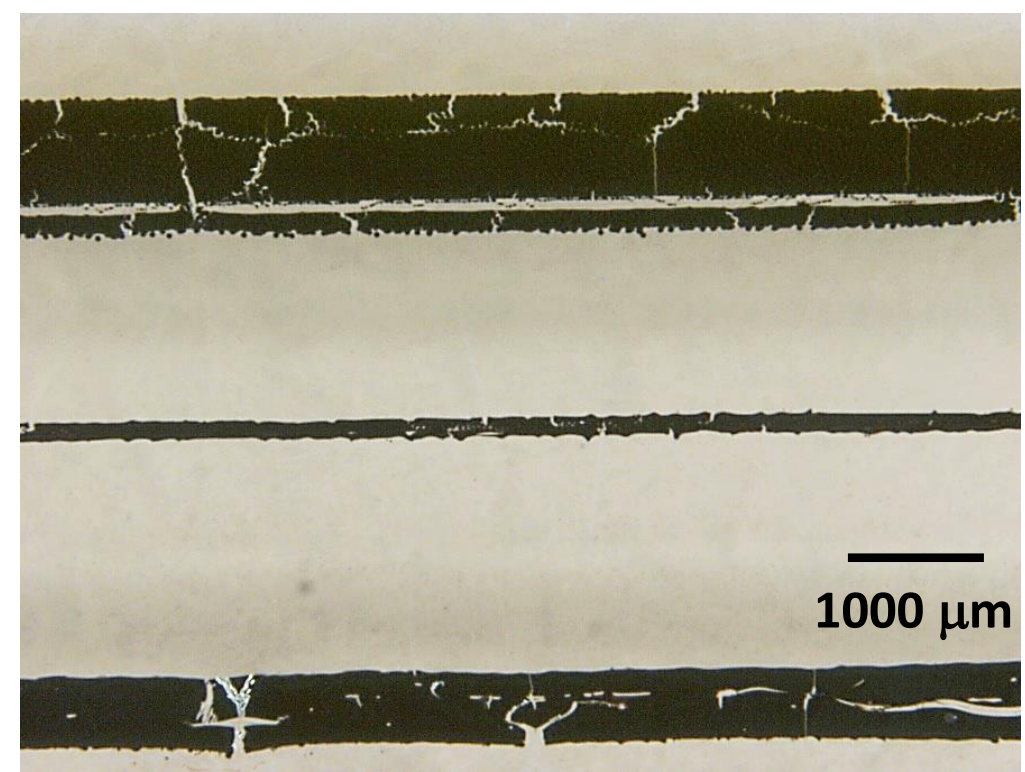

(A) 


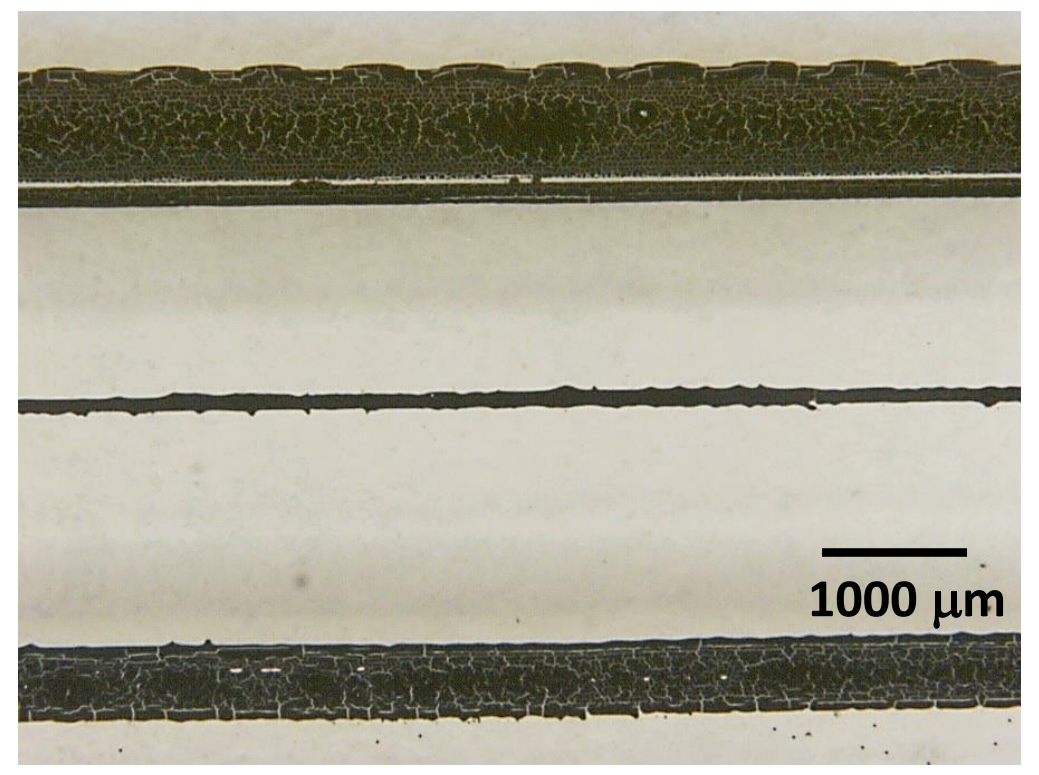

(B)

Fig. 4 Silver ink traces on EMD 6200 samples cured under: (A) Ambient atmosphere, followed by UV-ozone treatment (30 min); (B) Inert atmosphere followed by UV-ozone treatment (30 $\min )$. 


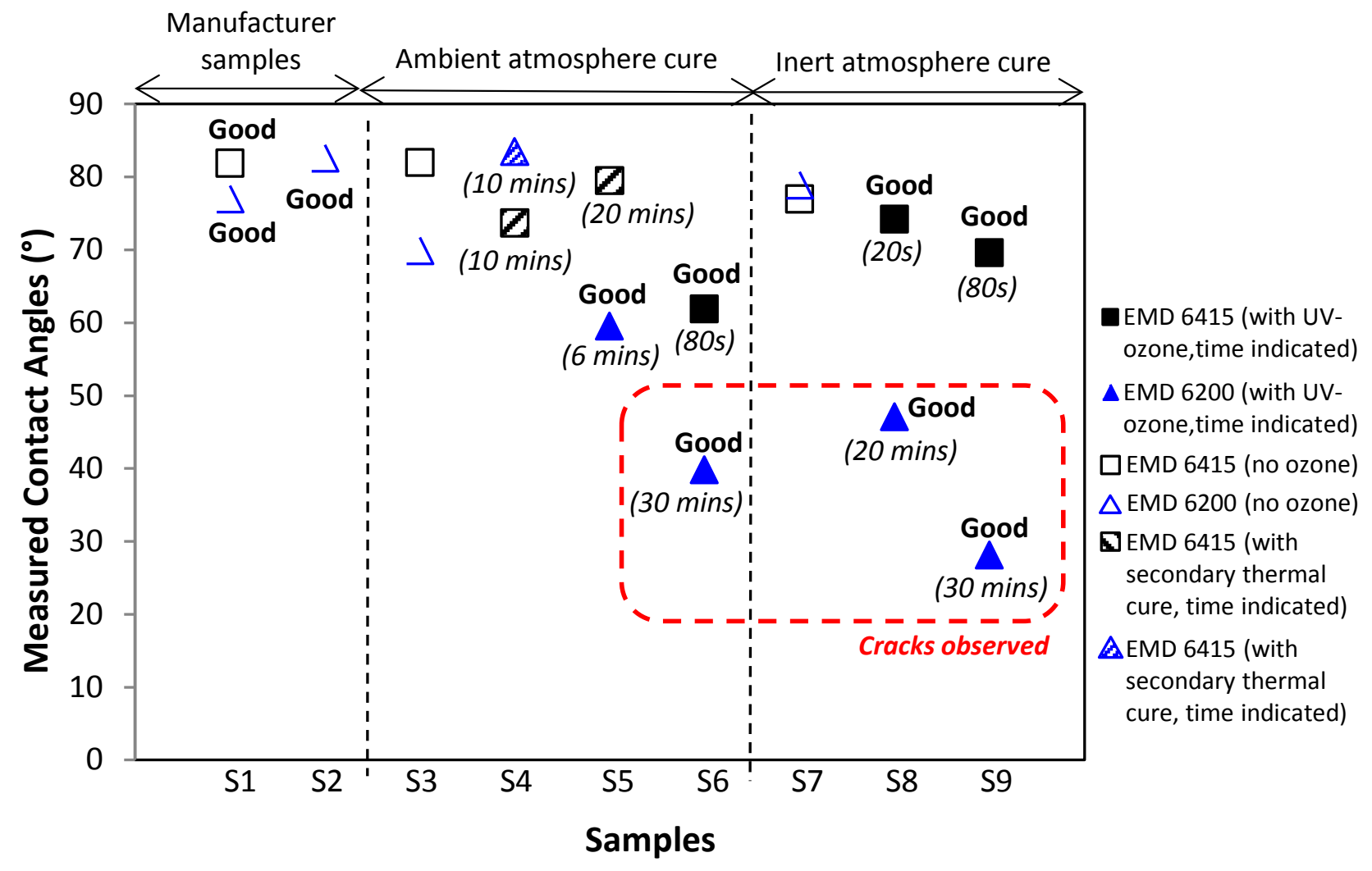

Fig. 5 Measured contact angles of water on dielectric layers prepared under different conditions. The notation “Good” refers to good silver ink printability where clear linear traces were obtained. 


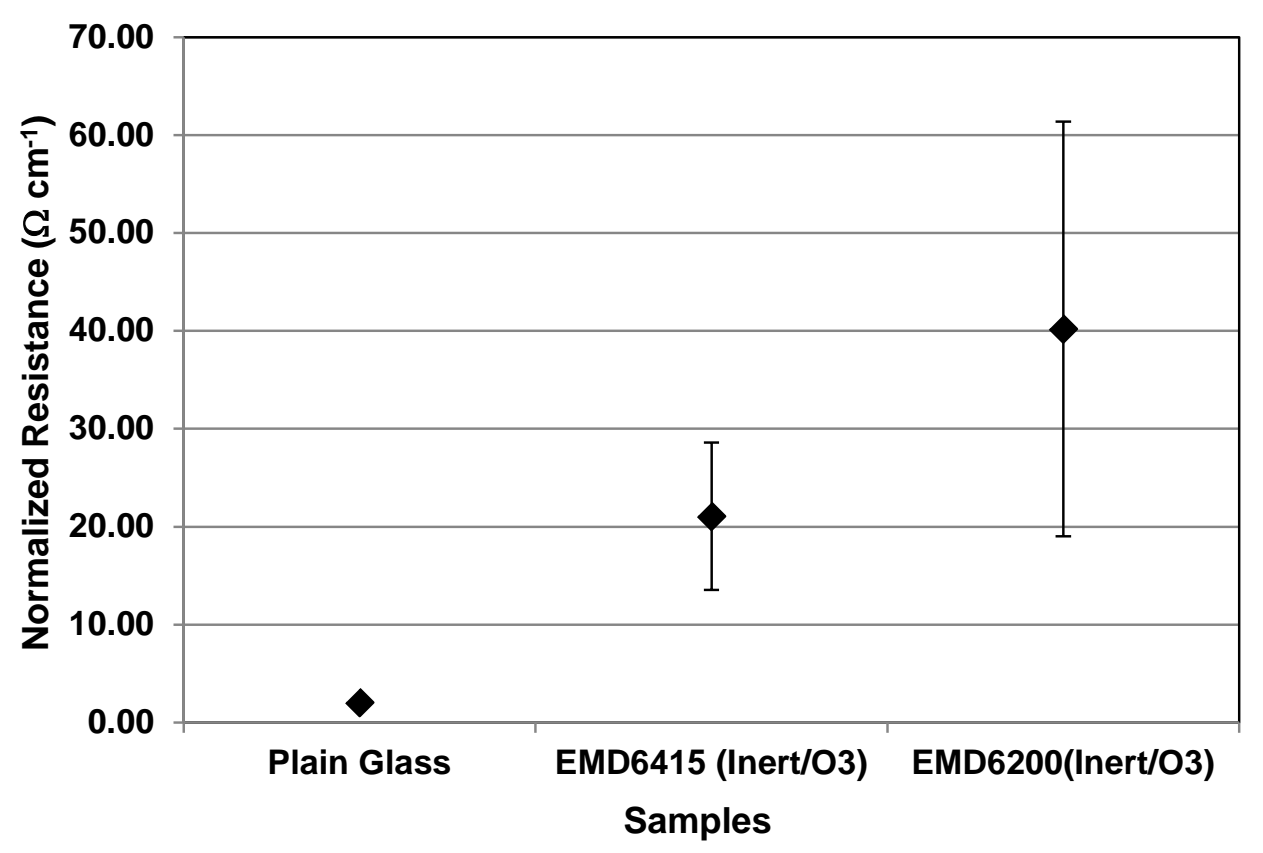

Fig. 6 Comparison of normalized resistance values for $1 \mathrm{~mm}$ wide (design width) silver traces printed on plain glass, EMD 6415 and EMD 6200 dielectric layers. The EMD 6415 and EMD 6200 samples were cured in an inert atmosphere with UV-ozone post treatments of $20 \mathrm{~s}$ and 2 min respectively. The errors bars in the figure represent the maximum and minimum values. 


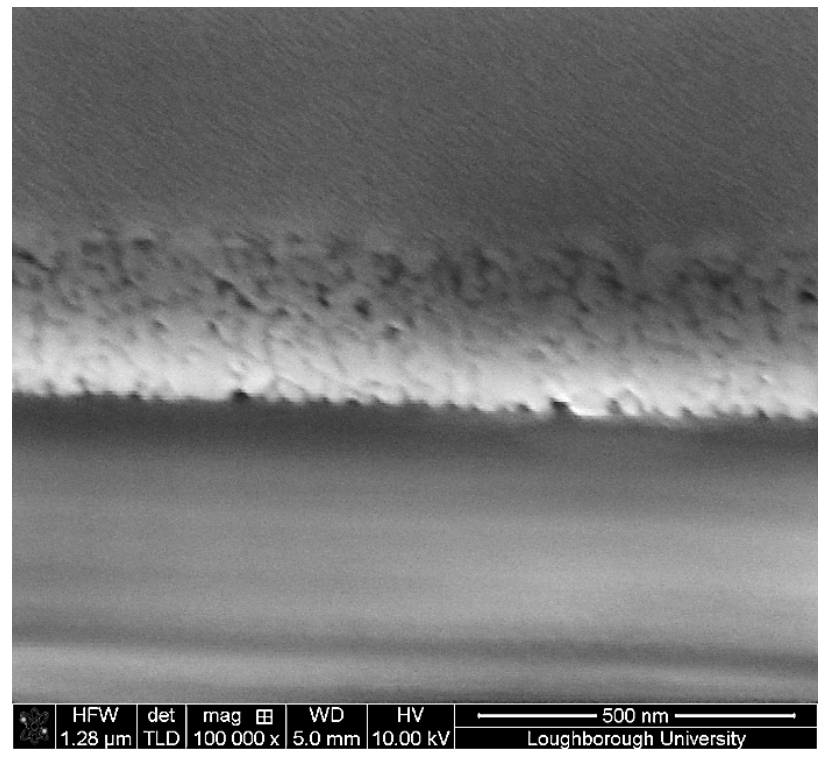

(A)

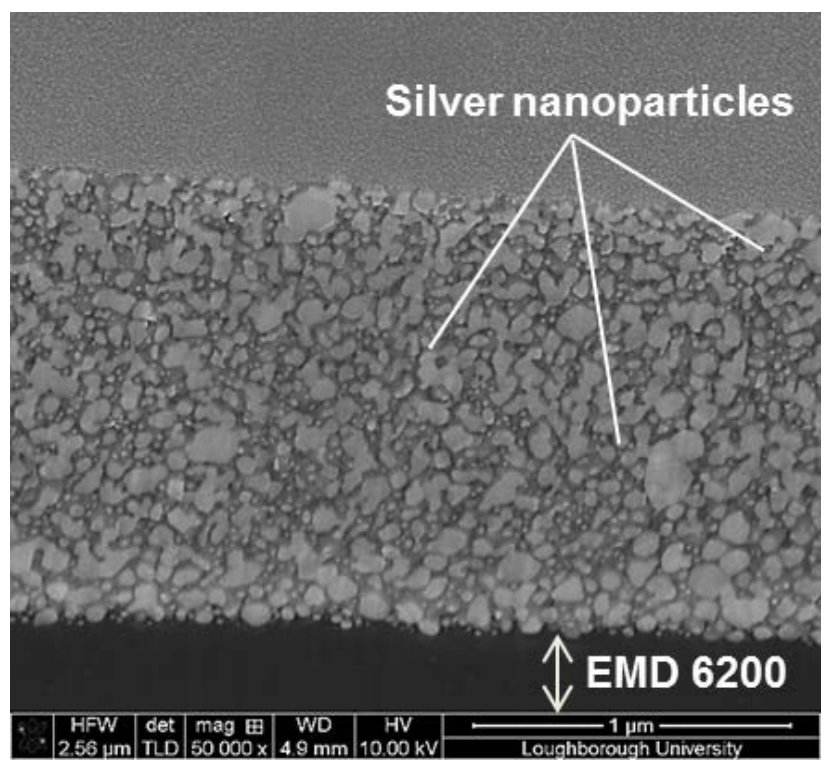

(B)

Fig. 7 FIB cross-section of sintered trace on: (A) plain glass; (B) EMD 6200 sample which was cured in an inert atmosphere and subjected to UV-ozone treatment for 2 min. 


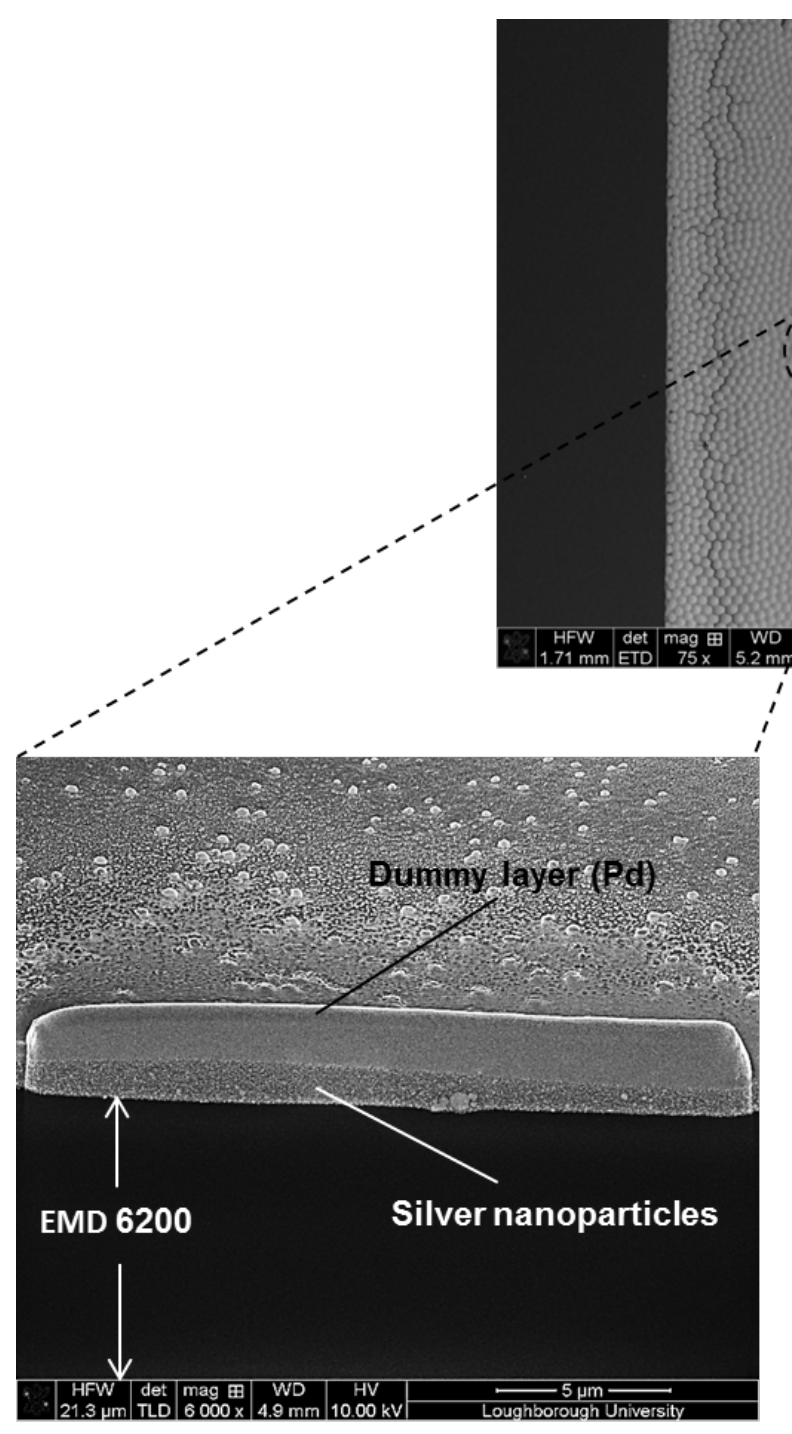

(B)

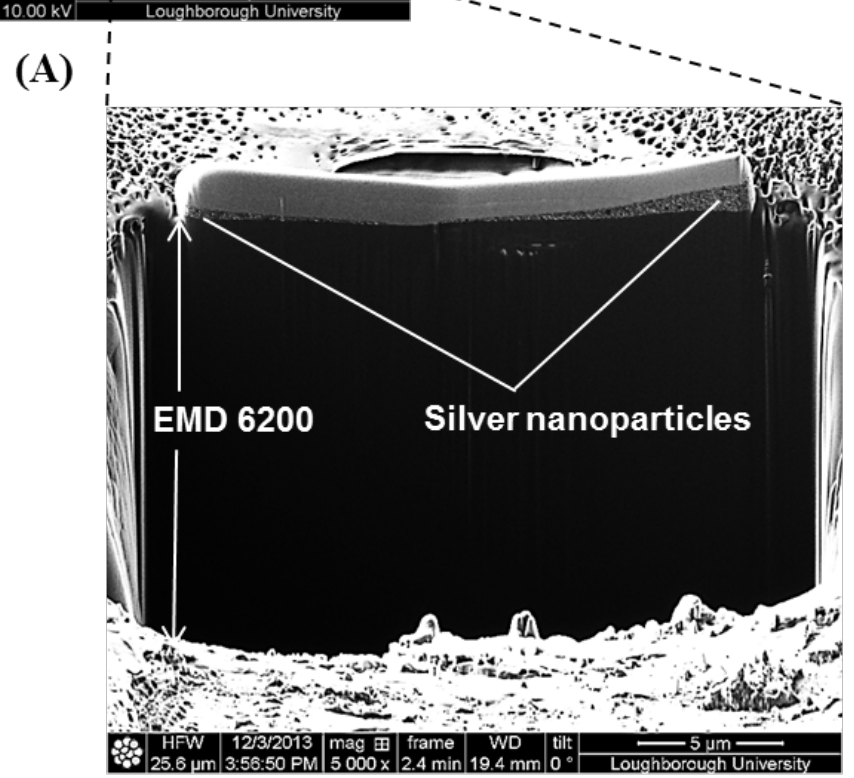

(C)

Fig. 8 Silver ink printed on EMD 6200 which was cured in an inert atmosphere and subjected to UV-ozone treatment for 2 min: (A) Top view of sintered trace; (B) Cross-section taken in the trace centre region; (C) Cross-section taken near the trace edge. 


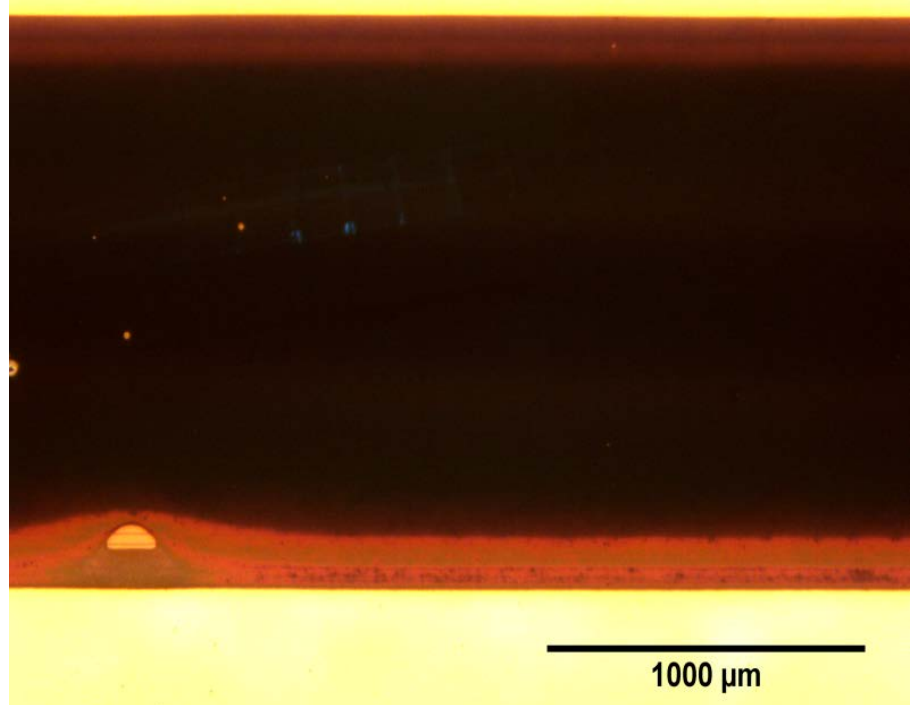

(A)

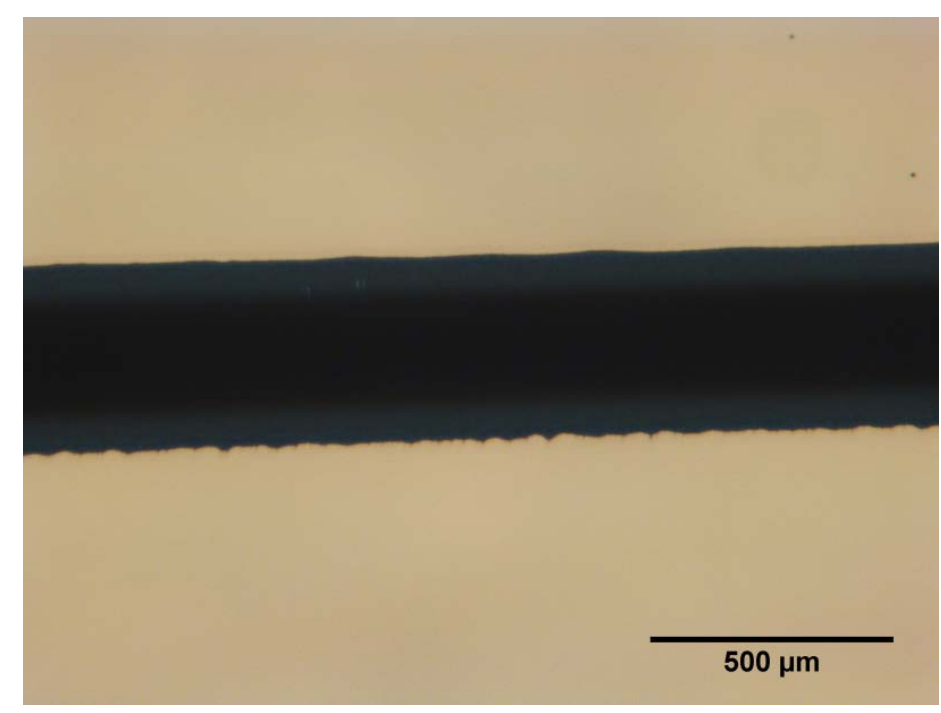

(B) 
Fig. 9 Silver traces overprinted onto ambient cured dielectric samples: (A) EMD 6415 sample exposed under an ambient atmosphere and followed with UV-ozone treatment (80 s); (B) EMD 6200 sample exposed under an ambient atmosphere and followed with UV-ozone treatment (6 $\min )$.

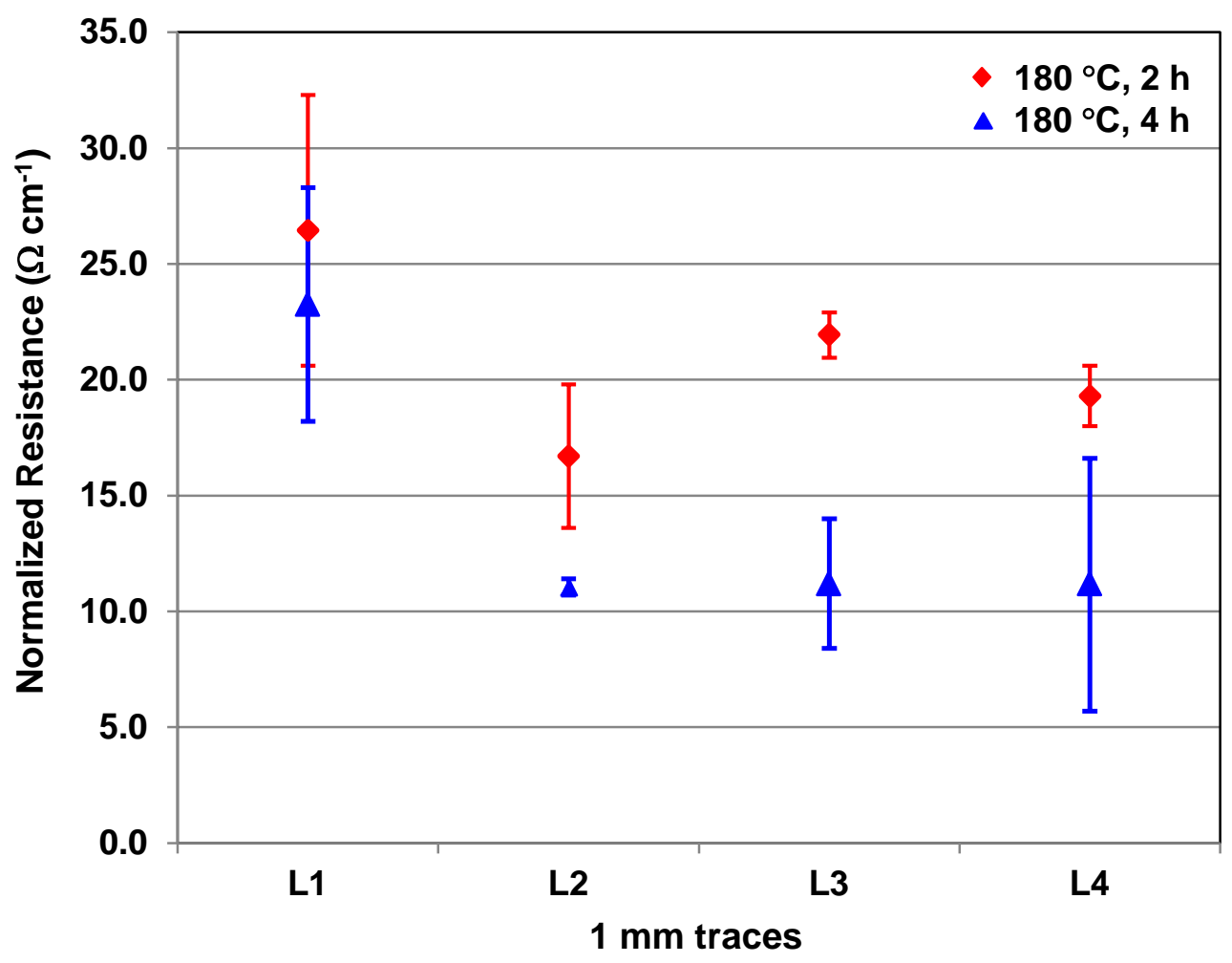

Fig. 10 Variation of the normalized resistance values for $1 \mathrm{~mm}$ wide (design width) silver traces sintered for different periods of time at $180^{\circ} \mathrm{C}$. The results are for two layers of silver overprinted on ambient cured EMD 6200 samples. 


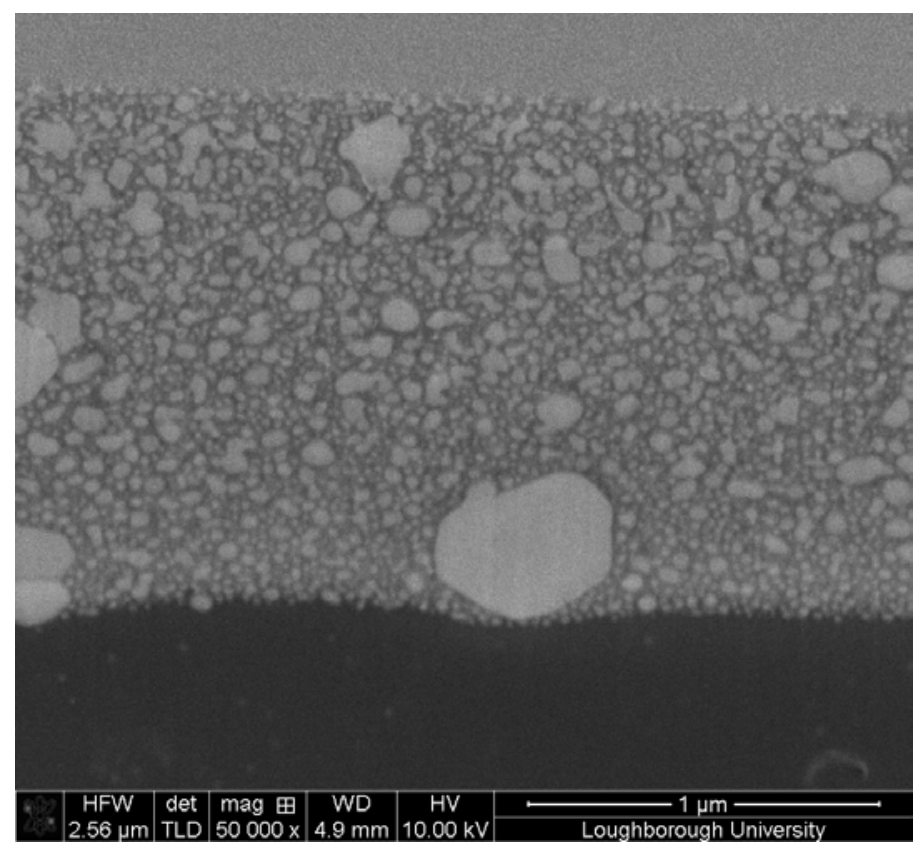

Fig. 11 FIB cross-section showing clusters of agglomerated silver nanoparticles observed for two layers of silver overprinted on an ambient cured EMD 6200 sample. 


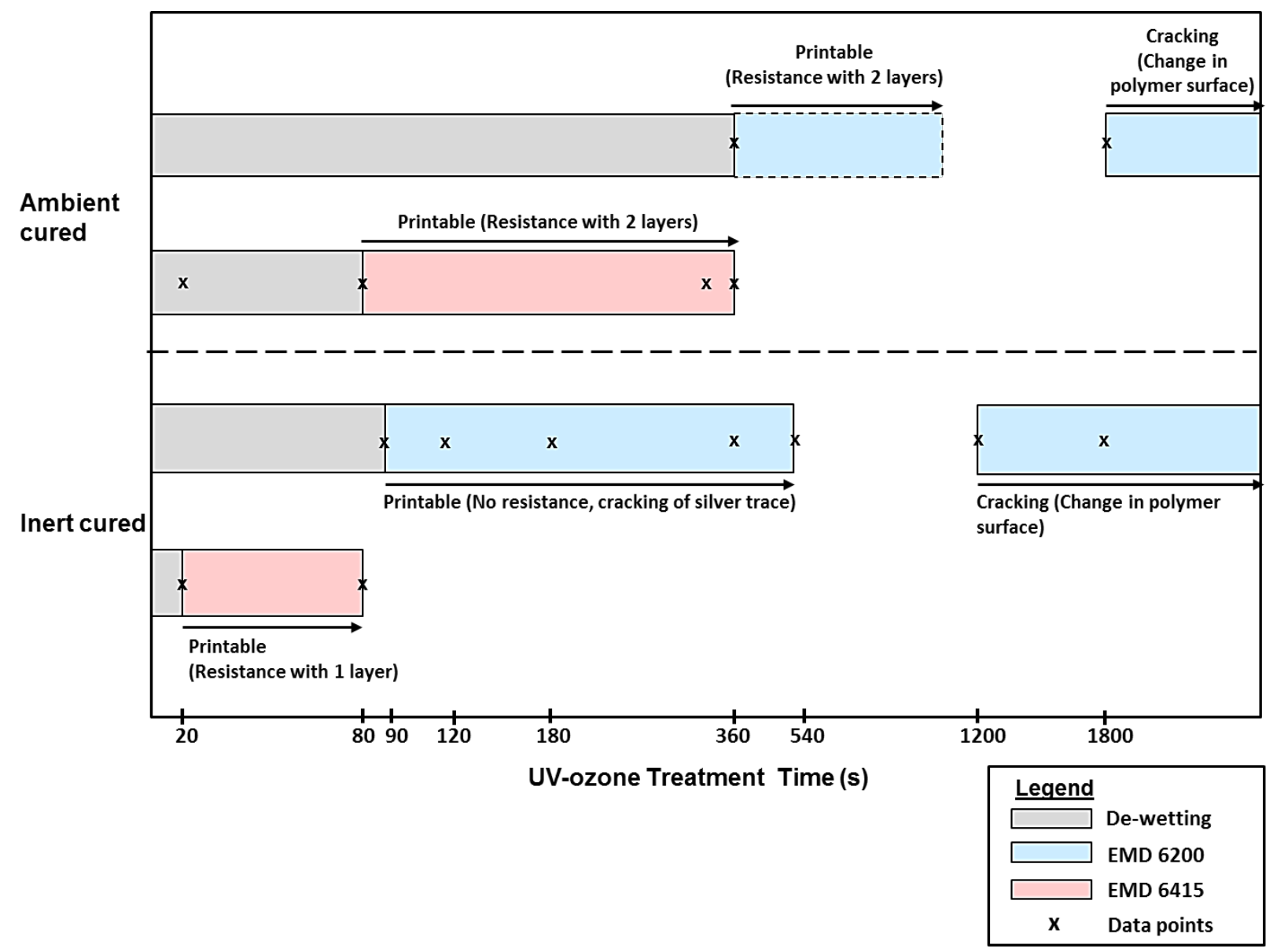

Fig. 12 Summary of the operating window for achieving printability and measurable resistance on UV-curable dielectric layers (UV cure dosages of $150-600 \mathrm{~mJ} / \mathrm{cm}^{2}$ ), with respect to the UVozone treatment time. 